\title{
LiMITED ARBITRAGE AND SHORT SALES RESTRICTIONS: EVIDENCE FROM THE OPTIONS MARKETS
}

\author{
Eli Ofek ${ }^{\mathrm{a}}$, Matthew Richardson ${ }^{\mathrm{b}}$ and Robert F. Whitelaw ${ }^{\mathrm{b}}$ *
}

\footnotetext{
* a Stern School of Business, New York University; ${ }^{b}$ Stern School of Business, New York University and NBER. We would like to thank Michael Brandt, Francis Longstaff, Lasse Pedersen and Eduardo Schwartz for helpful comments and suggestions and David Hait (Option Metrics) for providing the options data. Contact: Prof. Robert Whitelaw, $44 \mathrm{~W}$. $4^{\text {th }}$ St., New York, NY 10012; (212) 998-0338; FAX (212) 995-4233; rwhitela@stern.nyu.edu.
} 


\title{
LiMITED ARBITRAgE AND SHORT SALES RESTRICTIONS: EVIDENCE FROM THE OPTIONS MARKETS
}

\begin{abstract}
In this paper, we investigate empirically the well-known put-call parity no-arbitrage relation in the presence of short sale restrictions. We use a new and comprehensive sample of options on individual stocks in combination with a measure of the cost and difficulty of short selling, specifically the spread between the rate a short-seller earns on the proceeds from the sale relative to the normal rate (the rebate rate spread). We find statistically and economically significant violations of put-call parity that are strongly related to the rebate rate spread. Stocks with negative rebate rate spreads exhibit prices in the stock market that are up to $7.5 \%$ greater than those implied in the options market (for the extreme 1\% tail). Even after accounting for transaction costs in the options markets, these violations persist and their magnitude appears to be related to the general level of valuations in the stock market. Moreover, the extent of violations of put-call parity and the rebate rate spread for individual stocks are significant predictors of future stock returns. For example, cumulative abnormal returns, net of borrowing costs, over a $2 \frac{1}{2}-$ year sample period can exceed $70 \%$. It is difficult to reconcile these results with rational models of investor behavior, and, in fact, they are consistent with the presence of overoptimistic irrational investors in the markets for some individual securities.
\end{abstract}




\section{Introduction}

The concept of no arbitrage is at the core of our beliefs about finance theory. There is perhaps no better example in finance than the case of redundant assets, for example, stocks and options on those stocks. One of the most commonly cited no-arbitrage relations using stocks and options is that of put-call parity. The put-call parity condition assumes that investors can short the underlying securities. If short sales are not allowed, then this no-arbitrage relation can breakdown. Of course, even without short sales, the condition does not necessarily fail. Suppose that the stock is priced too high on a relative basis. Then one could form a portfolio by buying a call, writing an equivalent put, and owning a bond; the return on this portfolio would exceed the return on the stock in all possible circumstances. This is a difficult phenomenon to explain in "rational" equilibrium asset pricing models.

There is a considerable, and growing, literature that looks at the impact of short sales restrictions on the equity market. (See, for example, Lintner (1969), Miller (1977), Jarrow (1981), Figlewski (1981), Chen, Hong and Stein (2000), D’Avolio (2001), Geczy, Musto and Reed (2001), Mitchell, Pulvino and Stafford (2001), Ofek and Richardson (2001), Jones and Lamont (2001), and Duffie, Garleanu and Pedersen (2002), among others.) However, there has been much less attention paid to understanding the direct links between short sales and the options market (Figlewski and Webb (1993), Danielson and Sorescu (2001) and Lamont and Thaler (2000) are notable exceptions). Of particular interest to this paper, Lamont and Thaler (2000) document severe violations of put-call parity for a small sample of three stocks that have gone through an equity carve-out and the parent sells for less than its ownership stake in the carve-out. Lamont and Thaler (2000) view this evidence as consistent with high costs of shorting these stocks.

This paper provides a comprehensive analysis of put-call parity in the context of short sales restrictions. We employ two novel databases from which we construct matched pairs of call and put options and stock prices across the universe of equities, as well as a direct measure of the shorting costs of each of these stocks, namely their rebate rate. ${ }^{1}$ In

\footnotetext{
${ }^{1}$ In particular, when an investor shorts a stock, he (i.e., the borrower) must place a cash deposit equal to the proceeds of the shorted stock. That deposit carries an interest rate referred to as the rebate rate.
} 
this sample, we find significant violations of the put-call parity no-arbitrage restriction. ${ }^{2}$ For example, almost two thirds of stocks have prices greater than those implied by the options markets, with average deviations of $0.29 \%$ and the extreme $1 \%$ of deviations exceeding $4.4 \%$. These violations still persist even after incorporating shorting costs and/or extreme assumptions about transactions costs (i.e., all options transactions take place at ask and bid prices). For example, after shorting costs, $8.5 \%$ of stock prices still exceed the upper bound from the options market while only 3.9\% are below the lower bound.

Most important, under the assumption that the rebate rate maps one-to-one with the difficulty of shorting, we find a strong general relation between violations of no arbitrage and short sales restrictions. In particular, both the probability and magnitude of the violations can be linked directly to the magnitude of the rebate rate, or, in other words, the degree of specialness of the stock. For example, $69 \%$ of stocks with negative rebate rate spreads have prices that exceed those implied by the options market versus $63 \%$ for zero rebate spread stocks. Moreover, in a regression context, a one standard deviation decrease in the rebate rate spread implies a $0.7 \%$ increase in the deviation between the prices in the stock and options markets.

The above results suggest that the relative prices of similar assets (i.e., ones with identical payoffs) can deviate from each other when arbitrage is not possible. If we take the view that these deviations rule out our most standard asset pricing models, then what possible explanations exist? If markets are sufficiently incomplete, and there is diversity across agents, then it may be the case that these securities offer benefits beyond their riskreturn profiles (see, for example, Detemple and Jorion (1990), Detemple and Selden (1991), Detemple and Murthy (1977), and Basak and Croitoru (2000)). Alternatively, if markets are segmented such that the marginal investors across these markets are different, it is possible that prices can differ. Of course, in the absence of some friction preventing trading in both markets, this segmentation will not be rational.

\footnotetext{
${ }^{2}$ Related phenomena exist in other markets. For example, short-sellers of gold must pay a fee called the lease rate in order to borrow gold. This short-selling cost enters the no-arbitrage relation between forward and spot prices of gold as a convenience yield (see McDonald and Shimko (1998)). Longstaff (1995) examines transaction costs in the market for index options and shows that these costs can increase the implied cost of the index in the options market relative to the spot market.
} 
As an application, we provide evidence on this latter explanation by taking a simple framework in which the stock and options markets are segmented. Under particular assumptions, this allows us to interpret the differences between a stock's market value and its value implied by the options market. Assuming that the equity markets are "less rational" than the options markets, and using data on multiple option pairs, we are able to relate the magnitude of the mispricing to specific information about the ability to short sell (e.g., the rebate rate) and predicted maturity effects. These measures are then evaluated by their ability to forecast future movements in stock returns. Filtering on rebate rate spreads and measures of mispricing from the options market yields average returns on the stock over the life of the option that are as low as $-12 \%$. In addition, cumulative abnormal returns, net of borrowing costs, on portfolios that are long the industry and short stocks chosen using similar filters are as high as $70 \%$ over our sample period.

This paper is organized as follows. In Section II, we review the basics of put-call parity and the lending market, and then describe the characteristics of the data used in the study. Section III presents the main empirical results on the violations of put-call parity and their link to the short sale restrictions. In Section IV, we apply our analysis to imputing the overvaluation of stocks using evidence from the options market. Section V makes some concluding remarks.

\section{Preliminaries}

\section{A. Put-Call Parity}

Under the condition of no arbitrage, it is well known that, for European options on non-dividend paying stocks, put-call parity holds:

$$
S=P V(K)+C-P
$$

where $\mathrm{S}$ is the stock price, $\mathrm{PV}(\mathrm{K})$ is the present value of the strike price, and $\mathrm{C}$ and $\mathrm{P}$ are the call and put prices respectively on options with strike price $\mathrm{K}$ and the same maturity T. For American options, Merton (1973) shows that the puts will be more valuable because at every point in time there is a positive probability of early exercise. That is, 


$$
S \geq P V(K)+C-P
$$

There are essentially two strands of the literature that investigate equation (1) above. The first group of papers contains a series of empirical investigations (e.g., Klemkosky and Resnick (1979), Bodurtha and Courtadon (1986), Nisbet (1992), Kamara and Miller (1995), and Lamont and Thaler (2000)). The evidence from this literature is mixed but for the most part finds that put-call parity holds as described by equation (1). The second strand of the literature is concerned with analytical valuation formulas for American put options in which explicit values are given for the early exercise premium (e.g., Johnson (1983), Geske and Johnson (1984), Ho, Subrahmanyam and Stapleton (1994) and Unni and Yadav (1999)). Specifically, equation (1) can be rewritten

$$
S=P V(K)+C-P+E E P
$$

where EEP is the early exercise premium on the American put option.

At least two conditions must be met for equation (2) to fail. First, there must be some limits on arbitrage. The most commonly cited limit is short sale restrictions. Without short sales, if the stock price drifts above its implied price in the options market, then there does not exist an arbitrage that will automatically lead to convergence of the two values. There is a large, and growing, literature in finance that documents both the theoretical and empirical importance of short sales restrictions. ${ }^{3}$

Second, it must be possible that the values given by equation (2) can drift apart. That is, why would an investor purchase shares for $\$ \mathrm{~S}$ when he/she could duplicate the payoff of the stock using the bond market and call-put option pairs? Perhaps, it is too difficult or costly to replicate shares in the options market (e.g., transactions costs), or there is some hidden value in owning shares (e.g., Duffie, Garleanu and Pedersen (2001)), or, alternatively, options provide some additional value in terms of risk management due to markets being incomplete (e.g., Detemple and Selden (1991)).

The most popular explanation though lies at the roots of behavioral finance. Behavioral finance argues that prices can deviate from fundamental values because a significant part of the investor class is irrational. These irrational investors look to other information, e.g., market sentiment, or are driven by psychological (rather than financial) 
motivations. This class of investors has the potential to move asset prices, and, in the presence of limited arbitrage, there is no immediate mechanism for correcting these mispricings (see, for example, Shleifer (2000)). In the context of equation (2), if the equity and options markets are segmented, i.e., have different investors, then mispricings in the equity market do not necessarily carry through to the options market (see Lamont and Thaler (2000)).

In particular, as long as the investors in options are different than those in the equity market, and these investors believe there is a positive probability that asset prices will revert back to their fundamental price by the time the options expire, there can be a substantial difference between the market asset price and the implied asset price from the options market. Of course, these differences can only persist in the presence of limited arbitrage, whether that is due to transactions costs or, more directly, short sales restrictions. An interesting feature generated by the fixed expiration of the option is that, in a world of mean reversion to fundamental values, the maturity of the option can be an important determinant of the level of mispricing in equation (2).

In this paper, we investigate violations of equation (2) and relate it to the conditions described above, namely (i) limited arbitrage via either short sales restrictions or transactions costs, and (ii) potential periods of mispricing between equities and their corresponding options. This latter condition is evaluated by looking at both expected maturity effects in a mispriced world, potential structural shifts in mispricing, and the forecastability of future returns.

\section{B. The Lending Market}

There has been recent interest in the lending market for stocks. For example, D'Avolio (2001) and Geczy, Musto and Reed (2001) provide a detailed description and analysis of this market. Beyond the papers described in footnote 3 that show the potential theoretical effects of short sales restrictions and document empirical facts strongly

\footnotetext{
${ }^{3}$ See, for example, Lintner (1969), Miller (1977), Jarrow (1981), Figlewski (1981), Chen, Hong and Stein (2000), D'Avolio (2001), Geczy, Musto and Reed (2001), Ofek and Richardson (2001), Jones and Lamont (2001), and Duffie, Garleanu and Pedersen (2002) to name a few.
} 
relating short sales restrictions to stock prices, D'Avolio (2001) and Geczy, Musto and Reed (2001) present evidence that short sales restrictions exist and are not uncommon.

There are essentially two reasons why short sales restrictions exist, namely investors either are unwilling to sell stock short or find it too difficult to do so. In the former case, Chen, Hong and Stein (2000) provide a detailed account of why investors may be unwilling to short stock. In particular, they focus on an important group of investors, i.e., mutual funds, and argue that, though restrictions under the Investment Company Act of 1940 are no longer binding, mutual funds still abide by that act. In fact, they cite work that shows only a small fraction (2\%) of mutual funds short stocks, and provide evidence of greater mispricings when mutual funds are absent from the market.

In the latter case, there are both theoretical reasons and supporting empirical evidence that suggests it is difficult to short stocks on a large scale. First, in order to short a stock, the investor must be able to borrow it. In general, there are only a limited number of shares available for trading (i.e., a stock's float is finite), ${ }^{4}$ and someone (i.e., an institution or individual) would have to be willing to lend the shares. For whatever reason, individuals tend to lend shares less than institutions do. Second, there is no guarantee that the short position will not get called either through the lender demanding the stock back or a margin call. In this case, there is no guarantee that the investor will be able to re-short the stock.

One way to measure the difficulty in short selling is to compare the rebate rate against the corresponding money market rate. When an investor shorts a stock, he/she places a cash deposit equal to the proceeds of the shorted stock. That deposit carries an interest rate referred to as the rebate rate. If shorting is easy, the rebate rate closely reflects the prevailing market rate. However, when supply is tight, the rebate rate tends to be lower. This lower rate reflects compensation to the lender of the stock at the expense of the borrower, and thus can provide a mechanism for evening out demand and supply in the market. There are two ways in which we view the rebate rate in this paper. First, it can be used as the actual cost of borrowing a stock, and thus the rate can be employed in equation (2) in that context (e.g., Mitchell, Pulvino and Stafford (2001) and D'Avolio 
(2001)). Second, as pointed out by Geczy, Musto and Reed (2001) and Ofek and Richardson (2002), the lending market is not a typical well-functioning, competitive market. Thus, it may not be appropriate to treat rebate rates as competitive lending rates, and, instead, we use the rebate rate as a signal of the difficulty of shorting, i.e., the degree to which short sales restrictions are binding.

Alternatively, if investors are limited by how many shares they can short, there are other ways to bet against the stock. For example, one could imagine setting up a synthetic short position using the options market. Figlewski and Webb (1993) and Lamont and Thaler (2000) look at this case empirically. In the context of our discussion in Section II.A, we might expect to see violations of put-call parity as the standard no-arbitrage condition can be violated due to short sale restrictions and overvaluation of stocks. In this case, there would be excess demand for put options relative to call options, leaving a significant spread between the prices. As an extreme example, Lamont and Thaler (2000) show that, in the Palm/3Com case, the synthetic short for Palm (i.e., its implied value from options) was substantially lower than the traded price of Palm (approximately $30 \%$ less during the first few weeks). This is consistent with the equity prices reflecting one set of beliefs with the options market reflecting another set.

\section{Data}

This paper looks at put-call parity in the options market in conjunction with short sales restrictions as measured by the rebate rate. We employ two unique data sets over the sample period July 1999 to November 2001. Specifically, we look at daily data for 102 separate dates during this period that are approximately 5 business days apart. The sample is comprehensive to the extent it initially covers 6000 firms per day.

The first dataset comes from Option Metrics, who provide end-of-day bid and ask quotes, open interest, and volume on every call and put option across the universe of stocks (in some cases, 3 million option observations per month). Along with the options

\footnotetext{
${ }^{4}$ For example, there are only a limited number of shares issued by corporations. Moreover, insiders may be reluctant, or prevented, from selling. In the extreme case, for six months after an IPO, most of the shares have lockup restrictions.
} 
data are the corresponding stock prices, dividends and splits, as well as option-specific data such as implied volatilities, interest rates, maturities, and exercise prices.

The second data set includes the rebate rate for almost every stock in our sample. In particular, a financial institution, and one of the largest dealer-brokers, provided us with its proprietary rebate rates for the universe of stocks on the aforementioned selected dates. The sample is comprehensive because it includes the prices quoted to clients on a large number of firms, and it does not require that the bank have positions in these stocks. The rebate rate quoted represents an overnight rate and thus includes no term contracts, which are also possible in the lending market. For each day, we calculate the cost as the deviation from the "cold rate" for the day. We denote this cost as the rebate rate spread throughout the paper. Obviously, this spread will be zero for many firms.

Table 1A describes our entire sample of options that have both puts and calls with the same exercise price and maturity. Over the sample period, this sample includes a total of 1,129,103 option pairs. ${ }^{5}$ These pairs span 102 dates, with approximately 1000 firms per date and 10 option pairs per firm (an average of 2.5 different maturities and 4.2 different strike prices per maturity). The median and mean maturity of the options pairs are 110 and 157 days, respectively. The open interest on the call options tends to be larger than on the put options, with the mean and medians being 713 and 131 contracts respectively versus 479 and 62 . Note, however, that the daily volume can be quite low, especially for the put options. In particular, the mean and median volume for the call and puts respectively are 57 and 5 versus 48 and 0, respectively. Of course, even though over half the sample of puts on any day do not have volume, this does not mean that the bid and ask quotes do not represent accurate prices at which the options can be bought and sold. As a robustness check, we duplicated the analysis that follows only using options that had positive trading volume. While the sample sizes are much smaller, the results are qualitatively the same.

For the analysis, we further wish to restrict our sample to homogenous sets of option pairs. Therefore, we break up the sample into three maturity groups: (i) short (i.e., 30 to

\footnotetext{
${ }^{5}$ As a first pass at filtering the data, we looked only at options with maturities of at least 30 days on nondividend paying stocks. Moreover, we restrict ourselves to stocks on which (i) we have data on rebate rates, and (ii) there is positive open interest in both the put and call option. As is commonly done, we also put the options data through filters checking for recording errors.
} 
90 days), (ii) intermediate (i.e., 91 to 182 days), and (iii) long (i.e., 183-365 days). Furthermore, we focus on options that are close to at-the-money (i.e., $-0.1<\ln (S / K)<0.1){ }^{6}$ The majority of the analysis looks at the at-the-money, intermediate maturity option pairs. If there are multiple option pairs per stock on a given day that match the relevant maturity and moneyness filters, then we restrict ourselves to the option pairs that are closest to the middle of the range. This provides us with a maximum of one option pair per stock per date.

Table 1B provides a summary of the data for the at-the-money, intermediate maturity option pairs. The sample contains 66,408 pairs of options with median and mean expirations of slightly over 130 days. Compared to the larger sample, the open interest and volume for the calls and puts are of a similar magnitude. Of some interest to the analysis of put-call parity with transactions costs, the bid-ask spread of calls and puts in terms of their mean and median values range from $7.6 \%$ to $9.3 \%$. Thus, in the extreme case in which transactions only take place at ask and bid prices, these costs may be especially relevant.

Table 1B illustrates three other important features of the data. First, the implied volatilities of the stocks are quite high by historical standards, that is, almost $75 \%$ on average. Note that these implied volatilities are calculated using the Black-Scholes pricing model for call options assuming no dividends. Second, the early exercise premium for puts is relatively low, representing less than $1 \%$ of the value of the option on average. We use the method of Ho, Stapleton and Subrahmanyam (1994) to estimate this premium for each put option on each date. All the put-call parity conditions are then adjusted for this estimate as in equation (2). Finally, the mean and median annualized rebate rate spreads, conditional on being special, are $-1.55 \%$ and $-0.44 \%$, respectively. The interpretation of these values in terms of both the actual costs of shorting, and more generally as an indicator of the difficulty of shorting, are discussed in detail in the next section. Note that 20,430 (approximately 30\%) of the observations correspond to nonzero rebate rates.

\footnotetext{
${ }^{6}$ Note that we drop from the sample options with very long maturities and extreme moneyness. Also, to avoid other common problems associated with the data, we include stocks (i) with a stock price of at least
} 


\section{Put-Call Parity: Empirical Tests}

In this section, we perform an initial empirical analysis of equation (2). Ceteris paribus, without any underlying theory, we might expect $50 \%$ of the violations of equation (2) to be on either side. However, the limited arbitrage via short sales restrictions provides an asymmetry to equation (2). In particular, as stocks' market values rise above that implied by the options markets (if in fact that occurs), there is no arbitrage mechanism that forces convergence. On the other hand, if stock prices fall below their implied value, one can arbitrage by buying shares and taking the appropriate option positions. Thus, to the extent short sales constraints are binding, if prices deviate from fundamental value, equation (2) can be violated in one particular direction.

We provide three formal examinations related to equation (2). First, using the midpoints of the option prices and the closing price of the stock, we evaluate violations of equation (2). In addition, we directly relate these violations to the spread between the rebate rate and the prevailing market rate. To preview the major results, there are substantial violations of put-call parity, primarily in the direction of the asymmetry induced by binding short sales constraints.

Second, in order to better understand this latter point, we build the rebate rate into equation (2). Specifically, we assume the investor can short but at the cost of the rebate rate spread. This analysis is performed under different assumptions about the rebate rate process. While, by construction, this reduces the violations of equation (2), there still remain a significant number. Therefore, we investigate the relation between both the magnitude and direction of these violations and the rebate rate spread. The relation is positive and nonlinear, which suggests the rebate rate represents more than the actual cost of shorting.

Third, the analysis so far assumes transactions take place at prices at the midpoint of the quoted spread. As an alternative, we take an extreme view and assume that all purchases and sales in the options market are done at the ask and bid prices, respectively. This provides us with the strongest test of the put-call parity condition. We still document important violations though they are significantly reduced in number. While these 
transaction costs-based results cannot explain why stock prices and their option-implied values drift apart, it does explain why investors do not go to the options market to duplicate share purchases. Alternatively, to the extent prices deviate from fundamental values, these deviations are bounded by the magnitude of the transactions costs.

\section{A. Tests of Put-Call Parity}

We investigate equation (2) by taking the midpoint prices of all the option pairs in our filtered sample, the corresponding stock, and the prevailing market interest rate. Table 2 reports both the percentage number of violations of put-call parity in both directions, as well as estimates of the cross-sectional distribution of the traded stock price value divided by the option-implied stock price value. That is, in the latter case, we look at the ratio $R \equiv 100 \ln \left(S / S^{*}\right)$, where $\mathrm{S}^{*}=\mathrm{PV}(\mathrm{K})+\mathrm{C}-\mathrm{P}+\mathrm{EEP}$. To the extent that there are asymmetric violations due to short sales constraints, we would expect $R$ to exceed 0 .

There are several interesting observations one can make from the results reported in Table 2. First, in the sample period studied here, almost two-thirds of the sample violates put-call parity in the direction of $R$ exceeding 0 . As mentioned previously, ceteris paribus we would expect a $50 \%$ rejection rate. In fact, it is possible to show that, using a binomial model, the 5\% tail is approximately $50.04 \%$ - thus, the actual rejection rate of $64.86 \%$ is statistically significant at any measurable level. Second, consistent with this asymmetry, the median and mean of $R$ are 0.29 and 0.20 , respectively. While these estimates are significant at conventional levels, the magnitudes do not seem particularly large. Moreover, in studying the cross-sectional distribution of $R$, the $1 \%$ and $99 \%$ tails are 2.99 and 4.38 respectively. The tails of $R$ are asymmetric but not significantly so, further suggesting that while the violations occur, they tend not to be large.

Note that these observations look at the sample unconditionally. As discussed in Section II.A, deviations from fundamental value are not sufficient to generate violations of put-call parity. At a minimum, there must also be some form of limited arbitrage. Therefore, we break the sample into two distinct groups - one with rebate rate spreads equal to zero, and the other with negative rebate rate spreads. If negative spreads map 
one-to-one with short sales restrictions, then this partition represents one way to condition on stocks that are subject to limited arbitrage.

Table 2 reports the results using the rebate rate partitioning of the data. The first point to note is that of the 66,408 option pairs, 20,430 or approximately $31 \%$ of the observations have negative rebate rate spreads. Thus, difficulty in shorting stocks is a common phenomenon. Second, the option pairs with negative rebate rate spreads also have a greater percentage of put-call parity violations in the expected direction, that is, $69.12 \%$ versus $62.96 \%$. These differences are significant at any measurable level with a standard normal statistic equal to 15.35 . $^{7}$ Third, the median and mean of the ratio $R$ are significantly greater for these negative rebate rate stocks, i.e., 0.34 and 0.60 versus 0.16 and 0.16, respectively. Finally, most important, the tails of the distribution of $R$ show that, while the $1 \%$ tails are similar for the two samples (i.e., -3.17 versus -2.89 ), the $99 \%$ tails are dramatically different (i.e., 7.51 versus 2.78). The theory suggests that the distribution of $R$ should be asymmetric as the limited arbitrage appears through the difficulty in shorting stocks, i.e., when $S>S^{*}$. Extreme differences here are $5.0 \%$ when the rebate rate is below its normal rate.

There is reason to believe that rebate rate spreads are subject to some measurement error, suggesting that observations of small negative rebate rate spreads may not be that informative. ${ }^{8}$ Consequently, Table 2 also reports the distribution of $R$ for stocks with rebate rate spreads of less than $-1 \%$. The results are substantially more dramatic than when conditioning on negative spreads, with the mean of $R$ more than doubling to $1.24 \%$, the $99 \%$ tail increasing to over $11 \%$, and the proportion of positive violations exceeding $75 \%$. These results are consistent with the measurement error hypothesis, but they also suggest a relation between the magnitude of the spread and violations of put-call parity.

Table 2 documents three important facts: (i) there are a significant number of cases in which the rebate rate spread is negative, (ii) there are significant violations of put-call parity, and (iii) these violations are in some way related to negative rebate rate spreads. One natural question to ask is whether these put-call parity violations are consistent with

\footnotetext{
${ }^{7}$ All the statistical tests of rejection probabilities in the paper use the well-known DeMoivre-Laplace normal approximation to the binomial distribution. Given our sample sizes, this asymptotic approximation is essentially perfect.
} 
the magnitude of the rebate rate. That is, are the violations more likely and greater in magnitude when the stocks have lower rebate rates? This is an important question as there is some debate about the competitive nature of the equity lending market. In the next subsection, we bring evidence to bear on this question.

\section{B. The Rebate Rate and Put-Call Parity Violations}

If an investor is able to short, then we know that the rebate rate spread represents the actual cost of shorting. There is some debate, however, whether investors can actually locate and, equally important, maintain the short position when the stock is special, i.e., when its rebate rate spread is negative. Nevertheless, it seems worthwhile taking the view that the equity lending market is a competitive market, and that the rebate rate represents the market rate all investors can obtain. In other words, there is limited arbitrage only to the extent that the rebate rate spread is negative, i.e., short selling and, therefore, arbitrage is attainable but at a cost.

Including the cost of shorting stocks when they are special implies a revision of equation (2), namely

$$
S^{A} \equiv S(1-v)=P V(K)+C-P+E E P,
$$

where $v$ measures the spread between the rebate rate and the market rate. In theory, $v$ represents the cost of shorting the stock over the maturity of the option, which may or may not equal the current rebate rate spread. That is, one might expect the "specialness" to subside or get worse over time depending on current market conditions. Alternatively, even if a stock is not "special" today, there may be some expectation that it will be in the future. In theory, this expectation of future limits on arbitrage could drive a wedge between the equity and options market.

To better understand the properties of the rebate rate over the life of the option, we develop a particular rebate rate model and investigate its effect on put-call parity violations vis a vis equation (3). The model assumes that rebate rates follow a transition probability matrix between zero and negative rebate rate spreads (as estimated from the

\footnotetext{
${ }^{8}$ We elaborate further on this issue in the context of our later discussion of the piecewise linear regression results in Table 5.
} 
data). Conditional on a negative rebate rate spread, we assume an autoregressive time series model for the rebate rate over the next period (again estimated from the data). Thus, each period, we calculate the probability that the stock will go or remain special from week to week over the remaining life of the option, and then evaluate the cost that way. In particular, we estimate the average cost of shorting over the life of the option and plug this estimate into equation (3). The assumption we make here is that past rebate rate spreads, whether positive or not, are sufficient to describe the expected movements in these spreads. Table 3 reports the results from the estimation of the model.

Specifically, the probability transition matrix shows that, conditional on not being special, the probability of going special from week to week is very small, that is, approximately $2.52 \%$. However, conditional on going special, the probability is $89.9 \%$ that the stock stays special over the following week. The mean reversion of the negative rebate rate spread is quite slow (i.e., the $\mathrm{AR}(1)$ coefficient equals 0.90$)$. Thus, assuming the stock stays special and that its spread is highly negative, the rebate rate spread remains this way for a long time. This suggests that there are substantial costs to shorting certain stocks over the life of the option.

Under the rebate rate model, Table 4 reports the analog of Table 2's results in terms of put-call parity violations and the distribution of the magnitude of these violations, $R \equiv 100 \ln \left(\frac{S^{A}}{S^{*}}\right)$. By construction, the results in Table 4 decrease both the magnitude and the asymmetry of the put-call parity violations. In fact, at face value, this decrease is substantial. For example, the percentage of violations drop from $69.12 \%$ to $53.44 \%$ for stocks with negative rebate rate spreads, and from $62.96 \%$ to $53.87 \%$ for stocks that are not special. This suggests that the violation of put-call parity is very much bounded by the ability to conduct arbitrage. As the stock price drifts away from the corresponding options market, investors short the stock albeit at a cost, and prices move back together. However, this convergence is not supported by the evidence for the stocks with rebate rate spreads less than $-1 \%$. While the percentage of violations falls, it is still over $60 \%$, far greater than for the zero rebate rate spread sample.

This result aside, there are several other interesting observations one can make from Table 4. First, though there is a substantial reduction in the number of violations, 
the percentage of violations is still both economically and statistically significant. For example, the standard normal statistic for a test that the rejection rate for negative rebate rate spreads is $50 \%$ is 9.82 , which is significant at any reasonable significance level (i.e., it is a $10-\sigma$ event). Second, once the rebate rate model is incorporated into the analysis, the level of rejection rates between the zero and negative rebate stocks are statistically indistinguishable. Finally, and in contrast to the above point, the magnitude of the extreme rejections appears to be greater for the negative rebate rate sample even after all the rebate rate adjustments have been made. For example, the $99 \%$ tails for the negative rebate rate sample is 6.91 versus only 2.67 for the zero rebate rate sample. Moreover, the corresponding tail for stocks with spreads less than $-1 \%$ is still over $10 \%$. These differences at the extremes suggest equation (3) cannot represent the entire story.

In fact, equation (3) assumes that arbitrage takes place on an unlimited basis, albeit at the lower rebate rate. Suppose this is not the case. The results of Table 4 are consistent with this supposition, as put-call parity violations still exist. One explanation for these findings is that low rebate rates represent more the difficulty of shorting than the actual cost of shorting. We could argue, for example, that low rebate rates signify not only the shorting cost, but show that locating shorts, i.e., search costs, are extremely high. Take the extreme case in which it is almost impossible to locate a short, i.e., infinite search costs. The rebate rates are obviously not minus infinity in these cases.

One way to evaluate this point is to better understand the relation between put-call parity violations and the rebate rate spread. Table 5 reports results for both linear and piecewise linear regressions of $R$ on the rebate rate spread using the full sample, as well as conditioning on just negative rebate rate spreads. Most important, there is a strong negative relation between the rebate rate spread and $R$. While this is expected given the previous results, Table 5 allows us to quantify both the magnitude and statistical significance of this relation. For example, conditional on a negative rebate rate spread, consider the linear regression of $R$ on the rebate rate spread. In terms of the magnitude, a one standard deviation decrease in the rebate rate (i.e., $2.67 \%$ ) leads to a $0.71 \%$ increase in the relative mispricing between the stock price and its implied value from options. The corresponding t-statistic is over 50, which represents significance at any imaginable level. 
In the context of the above regression, one way to address the issue of whether the rebate rate measures the actual cost of shorting versus the difficulty of shorting would be to regress the rebate rate spread on $R$ for all the observations, but include a dummy variable for whether the rebate rate spread is zero. If the rebate rate proxies for the difficulty of shorting, then we would expect to see a discontinuity at zero. In other words, a very small but negative rebate spread should have different implications than a zero rebate rate spread. As expected, the coefficient on the rebate rate is the same. However, the dummy variable is statistically significant, albeit small, i.e., $-0.03 \%$. Thus, there is only a small jump in the magnitude of the violation once the rebate rate goes negative.

In the regression analysis so far, we have ignored two potentially important features: (i) the length of the option and therefore the predicted magnitude of the rebate rate over its life, and (ii) any nonlinearities that exist in the relation between $R$ and rebate rate spreads. In the former case, we repeat the regressions but now include the predicted rebate rate over the life of the option derived from the aforementioned model (e.g., see Table 3) instead of just the current rebate rate. This allows us to incorporate the maturity of the option, which might in turn effect the violations of put-call parity. The independent variable $\mathrm{Reb}^{\mathrm{A}}$ is expected cost of short selling over the life of the option, i.e., $-v$ in equation (3). Table 5 reports the results using the adjusted rebate rate. Both the explanatory power of the regressions (i.e., approximately 10\%) and the economic implications of the coefficient estimates are very similar with and without the adjustment. For example, a one standard deviation decrease (i.e., $0.17 \%$ ) in the adjusted rebate rate leads to an almost identical $0.70 \%$ increase in the relative mispricing between the stock price and its implied value from options. Interestingly, when the regression is performed over all the observations, including current zero rebate rate spreads with the potential for going special over a given maturity, the explanatory power drops. This suggests that the rebate rate model is not particularly helpful in explaining mispricings for zero rebate rate stocks. Finally, if the rebate rate reflects only the extra income that a holder of the stock can make by lending it out (see Duffie, Garleanu and Pedersen (2001)), then the coefficient should be less than or equal to one in magnitude. In both Models 2 and 4, the magnitudes of the coefficients are significantly larger than this bound, suggesting that something more is going on. 
One way to get at the nonlinear specification of the relation between $R$ and rebate rates is to consider a more general statistical model - here, we look at a piecewise linear regression with a dummy variable for zero spreads and various breakpoints at negative spreads. In particular, we choose breakpoints of $-0.5 \%$ and $-5.0 \%$ to reflect roughly the median and $95 \%$ levels of the rebate rate distribution. The corresponding regression equation is

$$
R_{i t}=\alpha_{0}+\alpha_{1} D_{i t}+\beta_{1} \operatorname{Reb}_{\mathrm{it}}+\beta_{2} \min \left(0, \operatorname{Reb}_{\mathrm{it}}+0.5\right)+\beta_{3} \min \left(0, \operatorname{Reb}_{\mathrm{it}}+5\right)+\varepsilon_{i t}
$$

Note that the coefficients represent the incremental change in the slope after the breakpoints. In other words, the slopes of the fitted relation over the rebate rate spread ranges $[-0.5 \%,-5 \%]$ and $[-5 \%, \infty]$ are $\beta_{1}+\beta_{2}$ and $\beta_{1}+\beta_{2}+\beta_{3}$, respectively. These results are also provided in Table 5. Several interesting observations can be made. First, though statistically significant, there is not very strong evidence of an economic, nonlinear relation at high negative rebate rate spreads. The difference in slope between the $-0.5 \%$ and $-5.0 \%$ breakpoints is only 0.06 . Second, and in contrast, there are sharp differences between rebate rates less than $-0.5 \%$ and slightly negative rebate rates. The slope is initially flat before reaching -0.31 after the first breakpoint. Note that this could be due to nonsynchronicity between rebate rate measurements across stocks during the day and interest rates. If the rebate rate is measured early in the day and interest rates subsequently increase, then the rebate rate spread will look negative even though it was actually zero at the time of the quote. This nonsynchronicity-induced measurement error potentially introduces a lot of noise into small negative rebate rate spread observations. Third, the dummy variable for whether the spread is negative or not jumps to $-0.08 \%$ from the aforementioned $-0.03 \%$, which suggests some (albeit small) support for the idea that the rebate rate measures more than just the actual cost of trading.

\section{Transactions Costs and Put-Call Parity Violations}

While the put-call parity arbitrage violations are reduced once the rebate rate is incorporated, it still cannot explain the price deviations between the stock price and its implied value from options. Over a given horizon, investors can choose to purchase shares directly or replicate their payoffs by going to the options market. Why would any 
investor choose the former if the latter market provides a much cheaper way of achieving the same payoffs? One possibility might be that the options market is too expensive to transact in, i.e., its lack of liquidity translates into high transactions costs. To investigate this hypothesis, we compare separately a long and short position in the stock versus the replication in the options market. In performing these calculations, we assume that the stock purchase is done at the last transaction price (be it a buy or a sell) and that one can borrow or lend at the same rate. In contrast, we assume purchases and sales of options are at the ask and bid prices, respectively. For example, we compare the prices of being long the stock to buying the call at its ask, selling the put at its bid, and lending the \$K strike price. That is,

$$
S^{L} \approx P V(K)+C^{A}-P^{B}+E E P,
$$

where $\mathrm{C}^{\mathrm{A}}$ and $\mathrm{P}^{\mathrm{B}}$ are the ask and bid prices of the call and put, and $\mathrm{S}^{\mathrm{L}}$ represents a long position in the stock. Similarly, a short position in the stock can be written as

$$
S^{S} \approx P V(K)+C^{B}-P^{A}+E E P,
$$

where $S^{S}$ represents a short position in the stock. Combining (5) and (6) together provides a bound on how much the stock price can drift:

$$
S^{S} \leq S \leq S^{L} .
$$

The results are reported in Table 6A. As is clear from Tables 2 and 4, there are many fewer cases in which the stock price is below its implied value, especially if we also condition on stocks facing limited arbitrage opportunities (i.e., negative rebate rate spreads). Thus, there are only a few cases in which the stock price drops below $\mathrm{S}^{\mathrm{S}}$. For example, only $2.67 \%$ of the observations have stock prices that violate this condition. In contrast, violations on the other side are more numerous, with $11.80 \%$ of the observations exceeding $\mathrm{S}^{\mathrm{L}}$. This means that, even in the presence of worst-case transactions costs (i.e., at ask and bid prices), it is cheaper to replicate payoffs using options than to purchase the shares directly. Why investors did not do this is a puzzle.

These results are even more dramatic when we partition the sample of observations into groups with and without negative rebate rate spreads. Assuming that negative rebate rate spreads proxy for short sales restrictions, Table $6 \mathrm{~A}$ shows that the violations are much more numerous for stocks that are short sale constrained. For example, the magnitude of put-call parity violations in the two samples is $18.78 \%$ versus 
$8.70 \%$ in trying to replicate a long position in the stock. This difference suggests that the equity market prices are drifting further from fundamentals because, without short sales, the prices cannot be either driven back down through equity market sellers or arbitraged away in the options market. The fact that they drift will be addressed in Section IV below. On the other side of equation (6), and consistent with the asymmetric nature of short sale constraints, the violations are virtually identical, i.e., $2.58 \%$ versus $2.71 \%$, for the two samples.

Section III.B and Table 4 show that the violations are substantially reduced once the rebate rate is incorporated into the cost of shorting. However, the results in Table 4 and the analysis drawn from Table 5 suggest that the rebate rate spread is not sufficient to avoid arbitrage between the options and equity markets. Thus, Table 6B looks at put-call parity violations assuming the rebate rate spread is a cost, as well as assuming that transactions take place at the bid and ask prices in the options market. Violations on the short sell side for negative rebate rate spread stocks are still more numerous, with $12.86 \%$ of the observations exceeding $\mathrm{S}^{\mathrm{L}}$ versus only $6.60 \%$ for zero rebate rate stocks. While the drop from $18.78 \%$ to $12.86 \%$ once rebate rates are incorporated is clearly significant, it also shows that, even with all transactions costs taken into account, there remain substantial violations of put-call parity. We feel this provides further evidence that the rebate rate spread represents more than just a cost of transacting, but also the difficulty of shorting in practice.

\section{Explaining the Put-Call Parity Violations: Empirical Analysis}

Several important implications can be drawn from the stylized facts of Section III. First, there is substantial evidence that across the universe of stocks there are limits to arbitrage. A significant percentage of these stocks face short sales restrictions, which have an effect on the ability to conduct arbitrage between the equity and options markets.

Second, and related, these limits to arbitrage do lead to violations of put-call parity such that stock prices and their corresponding implied values from options markets deviate from each other. Third, transactions costs, whether the actual cost of shorting or the bidask spread in the options market, seem to limit the magnitude of these deviations in many 
cases. Nevertheless, there still exist substantial violations of put-call parity. Moreover, even with transactions costs, the question of why the stock and options markets deviate in the first place remains.

There are a few theories in the finance literature that might help answer this question. For example, Duffie, Garleanu and Pedersen (2001) argue that stock prices can deviate from "fundamental value" because the stock price should also include the benefits derived from being able to lend out the stock to short-sellers. Of course, not all stocks can be shorted, so that the magnitude of this effect might be small. This point aside, put-call parity could be violated because the added benefit from the cash flow stream of possible share loans is similar to a stream of dividend payments. Dividends, if not accounted for, will lead to violations of equation (2).

Alternatively, the growing literature in behavioral finance also suggests a possible explanation. A number of papers (e.g., Miller (1977), Chen, Hong and Stein (2001), and Ofek and Richardson (2002), among others) show that, with investors having diverse beliefs and facing short sales constraints, prices can drift from fundamental values. The basic idea is the following: suppose there exists periods in which there are both overly optimistic investors and rational investors. The overly optimistic investors bid the prices of stocks up, but, due to the short sales constraints, the rational investors do not simultaneously bid the shares back down. Thus, the stock price tends to drift above the value associated with aggregate beliefs because there is no mechanism to push prices back to the true aggregate value.

Of course, the fact that stock prices drift from fundamental value does not necessarily lead to put-call parity violations. Why would these overly optimistic investors buy shares in the equity market when they could achieve the same payoffs at lower costs using options? One must also be willing to argue that the equity and options markets are sometimes segmented in terms of their investor classes; that is, these overly optimistic investors choose not to invest in the options market. Rational investors enter the options market, but, with short sales restrictions, cannot arbitrage between the two markets. The remainder of the paper focuses for the most part on building implications from this behavioral theory and then bringing evidence to bear on its validity. 
Note that, even in the above world with segmented markets, there still may not be put-call parity violations. Because option payoffs are based on the underlying share price, both the likelihood and magnitude of the put-call parity violation depends on the probability and degree to which stock prices will eventually revert to fundamental value. Consider the extreme case in which prices never revert to their fundamental value. In this case, put-call parity will not be violated, as options are derivatives of the stock and will reflect the stock price's actual stochastic process. This point is actually a powerful way to generate implications of the behavioral theory. Below, we describe three such implications and corresponding tests.

\section{A. The Maturity Effect of Put-Call Parity Violations}

Under the behavioral theory outlined above, and with short sales restrictions, put-call parity violations can occur if options investors have some belief that the stock price will revert to fundamental value. Consider rational investors who know everything about the fundamental stock price process, as well as the actual stock price process being driven by some degree of irrationality. The prices they pay in the options market (i.e., long puts, short calls) will reflect both the probability that stock prices will revert to fundamental value and the expected magnitude of this reversion over the life of the option. Thus, ceteris paribus, the maturity of the option should be very much related to the nature of the put-call parity violation. Note that the income story of Duffie, Garleanu and Pedersen (2001) will also produce a similar maturity effect.

Table 7 reports results several stylized facts related to put-call parity violations and the maturity of the options. Specifically, whereas previous tables focused on intermediate-term options with a median expiration of 131 days, we now look at options with three different ranges of maturities: (i) short- (i.e., 30 to 90 days), (ii) intermediate(i.e., 91 to 182 days), and (iii) long- (i.e., 183-365 days) maturity options (see the data description in Section II.C). . Given our other filters, this increases the overall number of option pairs from 66,408 to 160,117 over our sample period.

As can be seen from Table 7, the violations (both in number and magnitude) generally increase for longer maturity options. Specifically, the mean violation for long 
maturities is $0.35 \%$ versus $0.29 \%$ and $0.21 \%$ for medium and short maturity options, respectively. These differences get even stronger when we condition on negative rebate rate spreads. For example, the mean violations increase to $0.84 \%, 0.60 \%$ and $0.35 \%$, respectively. Thus, limited arbitrage matters but only to the extent that there is the possibility that prices will revert to fundamental values (as measured by the maturity of the option). Since the maturity effect describes more the magnitude of the violation, the percentage of violations is similar across maturities. These facts taken together suggest a strong relation between put-call parity violations and the option's maturity.

In order to better capture the magnitudes of these differences as the rebate rate spread gets more negative (i.e., the limits on arbitrage become greater), Figure 1 provides a graphical representation of the regression of $R$ on the rebate rate spread for the three partitions of the data - short, medium and long maturity options. As shown in the figure, significant put-call parity violations occur under two conditions: (i) negative rebate rate spreads (i.e., limited arbitrage), and (ii) long versus short maturity options (i.e., a higher probability of reversion). These results are consistent with the theory of behavioral biases amongst some investors in the equity market.

\section{B. Structural Shifts in Mispricing}

Section IV.A described and showed empirically why the put-call parity violation is related to the maturity of the option (at least in terms of the behavioral theory). However, the put-call parity violation is also related to the size of the disparity between the stock price and its fundamental value. That is, suppose all the conditions are met to satisfy the behavioral explanation. If the put-call parity violation is small, it could be because the maturity of the option is short (i.e., a low probability of reversion) or that the mispricing is small (i.e., the stock price reflects fundamental value).

To get at this latter point, it is worthwhile conditioning on periods of possible equity mispricing and then looking for violations of arbitrage in the options market. Of course, the difficulty with implementing such a test is that we do not know ex ante when these periods occur, if ever. Nevertheless, Table 8 reports three types of tests. First, as one possibility, we choose the so-called crash of the NASDAQ as the date of the structural 
shift in mispricing (i.e., the first two weeks of April 2000). We first calculate both the percentage and magnitude of put-call parity violations pre- and post-crash as defined by the pre-March 2000 and post-April 2000 periods, respectively. These results are reported in Table $8 \mathrm{~A}$. Specifically, conditional on negative rebate rate spreads, the mean and median levels of $R$ are $0.64 \%$ versus $0.58 \%$ and $0.48 \%$ versus $0.27 \%$, respectively, for pre- and post-crash. These differences are statistically significant at the $5 \%$ level. These results strongly suggest that put-call parity violations were affected by the NASDAQ crash. If the reader believes the crash was partly due to a correction in market mispricings, then these results are consistent with the aforementioned story of segmented markets, limited arbitrage and put-call parity violations.

Second, using the pre- and post-crash periods, we test formally for the relation between put-call parity violations and the rebate rate spread. Table $8 \mathrm{~B}$ provides regressions pre- and post-crash between the violations $R$ and rebate rate spreads, as well a formal test of the difference. Several points are important here. First, the constant in the regression is higher pre-crash than post-crash, reflecting the above result that larger violations of put-call parity are present in the earlier subsample. Second, the slope coefficient is larger in magnitude pre-crash, which suggests that these violations are more sensitive to the limited arbitrage restrictions. Of course, these restrictions are only relevant if mispricings do exist. The test for a structural change is strongly statistically significant.

Finally, in order to avoid specifying a particular date for the structural shift, we look at the relation between put-call parity violations and a continuous measure of mispricing, namely the P/E ratio of the S\&P500. While the P/E ratio reflects the present value of growth opportunities and therefore can vary for quite rational reasons, we treat high (low) $\mathrm{P} / \mathrm{E}$ ratios as reflective of overpricing (underpricing) for our purposes. Figure 2 graphs the median put-call parity violation magnitude for stocks with and without negative rebate rate spreads and the S\&P500 PE ratio on a quarterly basis.

Several observations are in order. First, and perhaps most interesting, the time series pattern in violations appears to match closely that of the PE ratio of the S\&P500, our measure of overvaluation. When the PE ratio is high, at the beginning of the sample period, put-call parity violations are relatively large in magnitude. As the PE ratio falls, 
the magnitude of violations also drops. The figure presents the data on a quarterly basis in order to smooth out some of the noise for presentation purposes, but, on a monthly basis, the correlation between the PE ratio and the median violation for negative rebate rate spread stocks is 0.77 . This somewhat casual evidence clearly suggests a strong and positive relation between valuation levels in the market and the magnitude of put-call parity violations. Second, consistent with Table 8, there appears to be a structural shift in the magnitude of these violations in mid 2000. Anecdotally, this time frame is associated with the so-called bursting of the tech bubble, which many researchers consider a period of mass overvaluation. Of course, the PE ratio also falls dramatically during this period. Third, before mid 2000, and after early 2001, the magnitudes of violations are fairly stable. The magnitudes are, however, at completely different levels. Again, this is consistent with the earlier period being governed by greater mispricings, and it also parallels the behavior of the PE ratio. Fourth, the difference in magnitudes between the groups conditioned on rebate rate spreads is interesting. There is always a substantial difference, which is consistent with the rebate rate spread proxying for limited arbitrage conditions. Interestingly, after early 2001, there are few violations for normal rebate rate stocks, which is consistent with the forces of arbitrage. However, during the so-called bubble period, substantial violations still take place for stocks with normal rebate rates (albeit less than for stocks with negative spreads). Recall that the stocks in our sample do not pay dividends, which generally puts many of our stocks in the technology sector. Even if the rebate rate is normal, and this suggests (though not definitively) that one can short the stock today, there might be an expectation that shorting will be difficult in the future. Thus, violations can still occur over the life of the option.

\section{Forecasting Returns}

Consider the behavioral model outlined above. In that world, option prices deviate from equity prices because rational investors price the assets in the options markets, and irrational investors price assets in the equity market. Arbitrage is not possible because investors cannot short in the equity market. Two factors limit the magnitude of the divergence between these markets: (i) some shorting (albeit at a cost) can take place, and 
(ii) there must be an expected convergence of these markets during the life of the option. With respect to this latter factor, this convergence suggests some form of predictability in stock returns. That is, assuming the rational investors accurately reflect the "truth" on average, we would expect stock returns to fall over the life of the option conditional on a put-call parity violation and/or a negative rebate rate spread. Our analysis is similar in spirit to that of Jones and Lamont (2001), who also look at the ability of short-selling costs to predict future returns. The key differences are that they examine a smaller crosssection of stocks (90 on average) for the period 1926-1933, and they condition only on short-selling costs and not on information from the options market. Nevertheless, their conclusions are similar.

Table 9A reports the average excess stock return over the life of the option, conditional on available information such as the current put-call parity violation, rebate rate spread, and combinations of these variables. ${ }^{9}$ The results show strong evidence that these mean excess returns are negative. For example, conditional on a negative rebate rate spread, the mean excess return over the life of the option is $-6.85 \%$ versus $0.21 \%$ for zero rebate rate stocks. The result is magnified if we condition on even greater rebate rate spreads, such as $-0.5 \%$ in which case the mean return drops to $-9.38 \%$. All of these results are strongly statistically significant. While of smaller magnitude, conditioning on put-call parity violations also provides similar results. For example, for violations greater than $0.0 \%$ and $1.0 \%$ respectively, the mean excess returns are $-2.71 \%$ and $-4.45 \%$ over the life of the option. Finally, to the extent that the rebate rate and the violation may contain some differential information about future stock price movements, the table also reports mean excess returns for combined partitions of the data. Generally, the excess returns are even more negative. For example, by conditioning on negative rebate rate spreads less than $-0.5 \%$, and combining that with put-call parity violations greater than $0.0 \%$ and $1.0 \%$, we find that excess returns fall from $-9.38 \%$ to $-10.59 \%$ and $-11.95 \%$, respectively.

To examine these relations more closely, Table 9B also reports more general tests of stock return predictability using both the rebate rate and the put-call parity violation $R$ as 
predictive variables. In particular, for each option pair, we take the excess return on the stock over the life of the option and regress it on these variables. Consider first the magnitude of the put-call parity violation. In theory, this difference represents the expected drop in risk-adjusted returns over the life of the option. Thus, to the extent that our measure of excess returns captures this risk-adjusted return, we would expect a coefficient of -1 , i.e., a one-for-one drop in returns per unit of overvaluation in the equity market. The estimate from the data is very close, i.e., -1.15 , and is statistically indistinguishable from -1 (with a standard error of 0.12).

With respect to the rebate rate spread, we run a regression of future excess returns on the rebate rate spread and on a dummy variable taking on the value of 1 if the rebate rate spread is zero. The results also suggest predictability of returns. However, the magnitudes are considerably greater with respect to the rebate rate spread. For example, a negative rebate rate spread alone suggests a 5.55\% drop in future expected returns over the life of the option. This is strongly significant with t-statistics in excess of 13 . The economic interpretation is that the mere difficulty in shorting corresponds to a $5.55 \%$ fall in future prices. In terms of the magnitude of the rebate rate, there is an almost one-for-one drop in stock returns per unit of the rebate rate spread. This result means that a one standard deviation drop in the rebate rate spread results in a drop of $2.65 \%$ in future expected returns on the stock over the life of the option. Note, however, that the rebate rate spread is an annualized number and does not take into account the maturity of the option or the possibility that rebate rates will change in the future. When we use the expected cost over the life of the option $\left(\operatorname{Reb}^{\mathrm{A}}\right)$ as the independent variable, the coefficients are more than an order of magnitude larger. The decline in the stock price over the life of the option is much greater than can be explained by the magnitude of shorting costs, assuming, of course, that our time series model for rebate rates is reasonable. Interpreting the adjusted rebate rate spread as the income (dividend) that can be generated by lending out the stock implies a negative coefficient, consistent with the results, but the magnitude should be less than 1 (Duffie, Garleanu and Pedersen (2001)). These results are consistent with

\footnotetext{
${ }^{9}$ The theory implies that the difference between the option-implied stock price and the market price reflects the excess risk-adjusted return. We measure this excess return on each stock by subtracting out the corresponding industry return over the life of the option.
} 
those of Jones and Lamont (2001), who also find in their sample that returns exceed the associated borrowing costs on the stock.

Another way to evaluate the forecastability of returns using these measures of limited arbitrage and short sales restrictions is to evaluate a trading strategy that takes all the relevant costs into account. In particular, let us assume that shorting can take place albeit at the rebate rate spread. We form five zero-investment different portfolios and follow their performance from week to week. In particular, we form a long portfolio of the relevant industry returns and a short portfolio of stocks satisfying one of five different criteria: (i) stocks with a negative rebate rate spread less than $-0.5 \%$, (ii) stocks with a negative rebate rate spread less than $-1.0 \%$, (iii) stocks with put-call parity violations, (iv) stocks with put-call parity violations greater than 1\%, and (v) stocks with both (i) and (iii). The portfolio has equal weights on all stocks satisfying the relevant criteria, and stocks are held until the expiration of the corresponding option. Each week, the return on the portfolio is adjusted for the costs of shorting as described by the actual rebate rate spreads on the stocks in the portfolio.

Figure 3 graphs the returns on portfolios 1, 3 and 5 over the sample period. Irrespective of the criteria, the portfolios of stocks (with short signals) perform miserably relative to the weighted portfolio of corresponding industry returns. Thus, the zero investment portfolio produces large excess returns. For example, the cumulative returns on portfolios 1, 3 and 5 are approximately 40\%,20\% and 70\%, respectively. As can be seen from the figure, the performance of the portfolio over the sample period suggests pervasive, and fairly consistent, poor returns on stocks that are subject to arbitrage constraints. We take this as evidence that there exist binding arbitrage constraints for a reason. Even if the above strategy is not implementable (i.e., the rebate rate represents more than just the cost of shorting), it presents a considerable puzzle to financial economists. Specifically, who is buying these arbitrage-constrained stocks at these inflated prices?

Table 10 documents the statistical properties of all five portfolios. While all the portfolios produce positive mean excess returns, the returns are highest the greater the arbitrage constraint. For example, changing the rebate rate criteria from $-0.5 \%$ to $-1.0 \%$ changes daily mean excess returns from $0.070 \%$ to $0.096 \%$. Interestingly, the volatilities 
across the portfolios are very similar. Thus, the standard risk-return tradeoff is not the source of these differences. While the means increase, the volatilities are stable at $1.02 \%$ and $1.03 \%$, respectively.

\section{Conclusion}

Shleifer (2000) argues that there are two necessary conditions for behavioral finance to have some chance of explaining financial asset prices, that is, for prices to deviate from fundamental value. The first is that some investors must be irrational, namely they must ignore fundamental information or process irrelevant information in forming trading decisions. The second is that there must be some limits to arbitrage such that this irrationality cannot get priced out of the market. In this paper, we look at a unique experiment that gets at these conditions. Specifically, by investigating the relation between equities and their corresponding options both under conditions of severe arbitrage constraints and little or no constraints, we are able to investigate this issue directly. The power of the analysis is greatly increased by looking across the universe of stocks over a three-year period.

We document several stylized facts that pose considerable problems for rational asset pricing models. First, there are significant periods and numbers of firms subject to short sales constraints. For example, we find that stocks have negative rebate rate spreads, i.e., some degree of specialness, over $31 \%$ of the time in our sample. Second, the more binding the constraint, the greater the put-call parity violation. Specifically, we show a strong relation between the rebate rate spread and the magnitude of the violation. This suggests a degree of mispricing across markets, although it is perhaps not arbitrageable. Third, these results are consistent with a behavioral explanation to the extent that both the number and magnitude of these violations seem related to periods of mispricing and expectations about these mispricings being eventually reversed.

One might conclude that the results in this paper support the foundations of behavioral finance, namely that there are enough irrational investors to matter for pricing assets. Researchers should find it heartening, however, that the forces of arbitrage do appear to limit the relative mispricing of assets. That is, there is a clear relation between 
arbitrage constraints (e.g., transactions costs, rebate rates and specialness in general) and the level of mispricing. On a more negative note though, it remains a puzzle why any investor would ever wish to purchase such poorly performing stocks. We hypothesize that any explanation based on completion of markets will be a difficult story to swallow. 


\section{References}

Basak, Suleyman and Benjamin Croitoru, 2000, Equilibrium mispricing in a capital market with portfolio constraints, Review of Financial Studies 13, 715-748.

Bodurtha, James N. and Georges R. Courtadon, 1986, Efficiency tests of the foreign currency options market, Journal of Finance 41, 151-162.

Chen, Joseph, Harrison Hong and Jeremy C. Stein, 2000, Breadth of ownership and stock returns, working paper, Harvard University.

Cox, John and Mark Rubinstein, Options Markets, 1985, Prentice-Hall, Englewood Cliffs, New Jersey.

D'Avolio, Gene, 2001, The market for borrowing stock, working paper, Harvard University.

Danielson, B. and S. Sorescu, 2001, Why do options introductions depress stock prices? A study of diminishing short sales constraints, Journal of Financial and Quantitative Analysis 36, 451-484.

Detemple, Jerome and P. Jorion, 1990, Option listing and stock returns: An empirical analysis, Journal of Banking and Finance 14, 781-802.

Detemple, Jerome and L. Selden, 1991, A general equilibrium analysis of option and stock market interactions, International Economic Review 32, 279-303.

Detemple, Jerome and S. Murthy, 1997, Equilibrium asset prices and no-arbitrage with portfolio constraints, Review of Financial Studies 10, 1133-1174.

Duffie, Darrell, Nicolae Garleanu and Lasse Pedersen, 2001, Securities lending, shorting and pricing, Journal of Financial Economics, forthcoming.

Figlewski, Stephen, 1981, The informational effects of restrictions on short sales; Some empirical evidence, Journal of Financial and Quantitative Analysis 16, 463-476.

Figlewski, Stephen and Gwendolyn P. Webb, 1993, Options, short sales, and market completeness, Journal of Finance 48, 761-777.

Geczy, Christopher C., David K. Musto and Adam V. Reed, 2001, Stocks are special too: An analysis of the equity lending market, working paper, Wharton School.

Geske, Robert and H.E. Johnson, 1984, The American put option valued analytically, Journal of Finance 34, 1511-1524.

Ho, T.S., Marti Subrahmanyam and R.C. Stapleton, 1994, A simple technique for the valuation and hedging of American options, Journal of Derivatives 1, 52-66.

Hong, Harrison and Jeremy C. Stein, 2001, Differences of opinion, short sales constraints and market crashes, Working paper, Harvard University.

Jarrow, Robert, 1981, Heterogeneous expectations, restrictions on short sales, and equilibrium asset prices, Journal of Finance, Vol. 35, 1105-1113.

Klemkosky, Robert C. and Bruce G. Resnick, 1979, Put-call parity and market efficiency, Journal of Finance 34, 1141-1155. 
Johnson, H.E., 1983, An analytic approximation of the American put price, Journal of Financial and Quantitative Analysis 18, 141-148.

Jones, Charles and Owen Lamont, 2001, Short sales constraints and stock returns, working paper, University of Chicago.

Kamara, Avraham and Thomas W. Miller, Jr., 1995, Daily and intradaily tests of European put-call parity, Journal of Financial and Quantitative Analysis 30, 519539.

Lamont, Owen and Richard Thaler, 2000, Can the market add and subtract? Mispricing in tech stock carve-outs, working paper, University of Chicago.

Lintner, John, 1969, The aggregation of investor's diverse jugdements and preferences in purely competitive strategy markets, Journal of Financial and Quantitative Analysis 4, 347-400.

Lonstaff, Francis, 1995, Option pricing and the martingale restriction, Review of Financial Studies 8, 1091-1124.

McDonald, Robert and David Shimko, 1998, The convenience yield of gold, working paper, Northwester University.

Merton, Robert C., 1973, The theory of rational option pricing, Bell Journal of Economics 4, 141-183.

Miller, Edward M., 1977, Risk, uncertainty, and divergence of opinion, Journal of Finance 32, 1151-1168.

Mitchell, Mark, Todd Pulvino and Erik Stafford, 2001, Limited arbitrage in equity markets, working paper, Harvard Business School.

Nisbet, Mary, 1992, Put-call parity theory and an empirical test of the efficiency of the London traded options market, Journal of Banking and Finance 16, 381-403.

Ofek, Eli and Matthew Richardson, 2001, DotCom mania: The rise and fall of internet stock prices, working paper, New York University.

Rubinstein, Mark, 1985, Nonparametric tests of alternative option pricing models using all reported trades and quotes on the 30 most active CBOE option classes from August 23, 1976 through August 31, 1978, Journal of Finance 40, 455-480.

Shleifer, Andrei, 2000, Clarendon Lectures: Inefficient Markets, forthcoming Oxford University Press.

Shleifer, Andrei and Robert W. Vishny, 1997, The limits of arbitrage, Journal of Finance $52,35-55$.

Unni, Sanjay and Pradeep Yadav, 1999, Market value of early exercise: Direct empirical evidence from American index option prices, working paper, University of Strathclyde. 


\section{Table 1: Sample Description}

Panel A reports descriptive statistics for the full sample of paired options. The data span 102 dates between July 1999 and November 2001. The total number of option pairs is $1,129,103$. Panel B reports descriptive statistics for the subsample of paired options with $\ln (\mathrm{S} / \mathrm{X})$ of less than $10 \%$ in absolute value, and maturity between 91 and 182 days. If multiple options pairs fit the criteria for a single firm on a given date, then only one pair is selected. The data span 102 dates between July 1999 and November 2001. The total

number of pairs in this subsample is 66,408 , of which 20,430 have negative rebate rate spreads $(\operatorname{Reb}<0)$.

Panel A: Full sample of paired options

\begin{tabular}{lrrrr}
\hline Variable & Mean & Median & 5 pct & 95 pct \\
\hline \hline Expiration (days) & 157.308 & 110.000 & 36.000 & 561.000 \\
Ln(S/K) (\%) & -2.880 & -2.411 & -56.226 & 50.456 \\
Open interest - call & 713.6 & 131 & 5 & 2655 \\
Open interest - put & 479.0 & 62 & 3 & 1645 \\
Daily volume - call & 57.3 & 5 & 0 & 209 \\
Daily volume - put & 47.9 & 0 & 0 & 175 \\
Number of firms per date & 1052.9 & 1094.5 & 922 & 1152 \\
Number of option expirations per firm & 2.5 & 2 & 1 & 5 \\
Number of strikes per expiration & 4.2 & 3 & 1 & 11 \\
\hline
\end{tabular}

Panel B: At-the-money, intermediate maturity sample of paired options

\begin{tabular}{lrrrr}
\hline Variable & Mean & Median & 5 pct & 95 pct \\
\hline \hline Stock price & 31.218 & 23.280 & 7.500 & 80.375 \\
Expiration (days) & 133.141 & 131.000 & 94.000 & 177.000 \\
Ln(S/K) (\%) & 0.039 & 0.000 & -7.796 & 7.812 \\
Open interest - call & 418.970 & 102.000 & 5.000 & 1534.000 \\
Open interest - put & 297.578 & 52.000 & 3.000 & 1080.000 \\
Volume - call & 42.240 & 5.000 & 0.000 & 159.000 \\
Volume - put & 40.781 & 1.000 & 0.000 & 153.000 \\
Spread - call (\% of mid) & 8.704 & 7.595 & 2.198 & 18.182 \\
Spread - put (\% of mid) & 9.302 & 8.000 & 2.299 & 20.000 \\
American put premium (\% of mid) & 0.806 & 0.685 & 0.181 & 1.768 \\
Implied volatility (\%) & 74.268 & 72.188 & 39.219 & 117.656 \\
Rebate rate spread (Reb $<0)$ & -1.547 & -0.44 & -6.14 & -0.02 \\
\hline
\end{tabular}




\section{Table 2: Distribution of Unadjusted Stock Price Ratios}

The table reports the distribution of the ratio $R \equiv 100 \ln \left(S / S^{*}\right)$ for at-the-money, intermediate maturity options, where $S$ is the stock price and $S^{*}$ is the stock price derived from the options market using put-call parity and assuming trades of options at the midpoint of the spread. The four test statistics and corresponding P-values test: (1) the equality of the mean ratios across zero $(\operatorname{Reb}=0)$ and negative rebate spread $(\operatorname{Re} b<0)$ stocks, (2) \& (3) whether the probability of observing $R>0$ equals $50 \%$ for the zero and negative rebate spread stocks, and (4) whether the probability of observing $R>0$ is equal across zero and negative rebate spread stocks. The test statistics have an asymptotic $\mathrm{N}(0,1)$ distribution under the null hypotheses.

\begin{tabular}{rrrrr}
\hline & All & Reb $=\mathbf{0}$ & Reb $<\mathbf{0}$ & Reb $<-\mathbf{1 \%}$ \\
\hline \hline Obs & 66408 & 45978 & 20430 & 7113 \\
Mean & 0.29 & 0.16 & 0.60 & 1.24 \\
\hline Percentiles & & & & \\
1 & -2.99 & -2.89 & -3.17 & -3.57 \\
5 & -1.21 & -1.17 & -1.28 & -1.40 \\
10 & -0.67 & -0.67 & -0.69 & -0.69 \\
25 & -0.17 & -0.18 & -0.13 & 0.02 \\
50 & 0.20 & 0.16 & 0.34 & 0.78 \\
75 & 0.64 & 0.52 & 0.99 & 1.80 \\
90 & 1.31 & 1.02 & 1.99 & 3.41 \\
95 & 1.94 & 1.46 & 2.97 & 5.22 \\
99 & 4.38 & 2.78 & 7.51 & 11.23 \\
\hline $\mathrm{R}<0(\%)$ & 35.14 & 37.04 & 30.88 & 24.41 \\
$\mathrm{R}>0(\%)$ & 64.86 & 62.96 & 69.12 & 75.59 \\
\hline
\end{tabular}

\begin{tabular}{lrr}
\hline Test & Stat & P- value \\
\hline \hline $\mathrm{E}[\mathrm{R} \mid \mathrm{Reb}=0]=\mathrm{E}[\mathrm{R} \mid \mathrm{Reb}<0]$ & 27.28 & 0.00 \\
$\operatorname{Pr}(\mathrm{R}>0 \mid \mathrm{Reb}=0)=50 \%$ & 55.59 & 0.00 \\
$\operatorname{Pr}(\mathrm{R}>0 \mid \operatorname{Reb}<0)=50 \%$ & 54.67 & 0.00 \\
$\operatorname{Pr}(\mathrm{R}>0 \mid \mathrm{Reb}=0)=\operatorname{Pr}(\mathrm{R}>0 \mid \mathrm{Re} b<0)$ & 15.35 & 0.00 \\
\hline
\end{tabular}




\section{Table 3: Distribution and Time Series Model of Rebate Rate Spreads}

The table reports the cross-section and time series properties of the rebate rate spreads. The analysis is done on the rebate spread, which is the difference between the actual rebate rate on a stock and the rebate rate on "cold stocks" that day. There are a total of 694,911 daily observations. They include 7717 unique firms on 102 dates during the period July 1999 to November 2001. Panel A provides descriptive statistics on the distribution of the rebate spread for the entire sample. Panel B reports the 1-period transition probabilities between zero and negative rebate spread states. Panel $\mathrm{C}$ reports estimates of an $\mathrm{AR}(1)$ model for rebate spreads condition on spreads being negative (standard errors are in parentheses).

Panel A: Distribution of rebate rate

\begin{tabular}{rrrrrr}
\hline & Obs & Mean & Median & 5 pct & 95 pct \\
\hline \hline Reb $=0$ & 560128 & 0.00 & 0.00 & 0.00 & 0.00 \\
Reb $<0$ & 134783 & -4.30 & -1.11 & -13.59 & -0.02 \\
\hline
\end{tabular}

Panel B: Switching probabilities between negative and 0 spreads

\begin{tabular}{llrr}
\hline Period & & \multicolumn{2}{c}{$\boldsymbol{t + 1}$} \\
& & Reb=0 & Reb $<\mathbf{0}$ \\
\hline \hline $\boldsymbol{t}$ & Reb=0 & 97.48 & 2.52 \\
& Reb $<\mathbf{0}$ & 10.14 & 89.87 \\
\hline
\end{tabular}

Panel C: AR(1) model of rebate spread $<0$

$\mathrm{E}\left[\mathrm{Reb}_{\mathrm{t}} \mid \operatorname{Reb}_{\mathrm{t}-1}=0, \mathrm{Reb}_{\mathrm{t}}<0\right] \quad-1.845$

\begin{tabular}{ccccc}
\hline & Const & Reb $_{\mathrm{t}-1}$ & Rsq & Obs \\
\hline \hline Reb $_{\mathbf{t}}$ & $-0.567^{\mathrm{a}}$ & $0.904^{\mathrm{a}}$ & 0.715 & 117977 \\
& $(0.025)$ & $(0.002)$ & & \\
\hline
\end{tabular}

a - Significant at the $1 \%$ level 


\section{Table 4: Distribution of Stock Price Ratios Adjusted for Rebate Costs}

The table reports the distribution of the ratio $R \equiv 100 \ln \left(S^{A} / S^{*}\right)$, where $S^{A}$ is the stock price less the cost of the expected rebate rate spread over the life of the option using the 2-state AR(1) model estimated in Table 3 and $S^{*}$ is the stock price derived from the options market using put-call parity and assuming trades of options at the mid point of the spread. The four test statistics are described in Table 2.

\begin{tabular}{rrrrr}
\hline & All & Reb $=\mathbf{0}$ & Reb $<\mathbf{0}$ & Reb $<-\mathbf{1 \%}$ \\
\hline \hline Obs & 66408 & 45978 & 20430 & 7113 \\
Mean & 0.12 & 0.05 & 0.27 & 0.75 \\
\hline Percentiles & & & & \\
1 & -3.17 & -3.02 & -3.53 & -4.01 \\
5 & -1.39 & -1.28 & -1.61 & -1.84 \\
10 & -0.85 & -0.77 & -1.00 & -1.13 \\
25 & -0.33 & -0.29 & -0.41 & -0.40 \\
50 & 0.05 & 0.05 & 0.06 & 0.34 \\
75 & 0.47 & 0.41 & 0.66 & 1.28 \\
90 & 1.10 & 0.91 & 1.57 & 2.83 \\
95 & 1.67 & 1.34 & 2.47 & 4.57 \\
99 & 3.96 & 2.67 & 6.91 & 10.69 \\
\hline $\mathrm{R}<0(\%)$ & 46.26 & 46.13 & 46.56 & 38.42 \\
$\mathrm{R}>0(\%)$ & 53.74 & 53.87 & 53.44 & 61.58 \\
\hline
\end{tabular}

\begin{tabular}{lrr}
\hline Test & Stat & P-value \\
\hline \hline $\mathrm{E}[\mathrm{R} \mid \mathrm{Re} b=0]=\mathrm{E}[\mathrm{R} \mid \mathrm{Reb}<0]$ & 14.08 & 0.00 \\
$\operatorname{Pr}(\mathrm{R}>0 \mid \mathrm{Reb}=0)=50 \%$ & 16.59 & 0.00 \\
$\operatorname{Pr}(\mathrm{R}>0 \mid \mathrm{Re} b<0)=50 \%$ & 9.82 & 0.00 \\
$\operatorname{Pr}(\mathrm{R}>0 \mid \mathrm{Re} b=0)=\operatorname{Pr}(\mathrm{R}>0 \mid \operatorname{Reb}<0)$ & -1.03 & 0.85 \\
\hline
\end{tabular}




\section{Table 5: Regressions for Unadjusted Stock Price Ratios}

Panel A reports linear regressions of the stock price ratio on rebate rate spreads. The dependent variable is the ratio $R \equiv 100 \ln \left(S / S^{*}\right.$ ) (see Table 2). The independent variables are a zero rebate spread dummy that equals 1 if the firm has a zero rebate spread that day and 0 otherwise, the rebate spread for the firm that day (Reb), and the adjusted rebate spread for the firm that day $\left(\operatorname{Reb}^{\mathrm{A}}\right)$, which is the average expected rebate rate spread over the life of the option using the 2-state AR(1) model estimated in Table 3. Panel B reports a piecewise linear regression of the stock price ratio on the zero rebate spread dummy and the rebate spread with 2 breakpoints at rebate spreads of $-0.5 \%$ and $-5 \%$ (see equation (4)). Standard errors are in parentheses.

\section{Panel A: Linear regressions}

\begin{tabular}{|c|c|c|c|c|c|c|c|}
\hline & Sample & Const & Dummy & Reb & $\operatorname{Reb}^{\mathbf{A}}$ & Rsq & Obs \\
\hline Model 1 & $\operatorname{Reb}<0$ & $\begin{array}{l}0.188^{\mathrm{a}} \\
(0.017)\end{array}$ & & $\begin{array}{l}-0.267^{\mathrm{a}} \\
(0.005)\end{array}$ & & 0.108 & 20430 \\
\hline Model 2 & $\operatorname{Reb}<0$ & $\begin{array}{c}-0.75^{\mathrm{a}} \\
(0.031)\end{array}$ & & & $\begin{array}{l}-4.103^{\mathrm{a}} \\
(0.083)\end{array}$ & 0.107 & 20430 \\
\hline Model 3 & All & $\begin{array}{l}0.188^{\mathrm{a}} \\
(0.012)\end{array}$ & $\begin{array}{c}-0.031^{b} \\
(0.014)\end{array}$ & $\begin{array}{c}-0.267^{\mathrm{a}} \\
(0.004)\end{array}$ & & 0.078 & 66408 \\
\hline Model 4 & All & $\begin{array}{l}-0.226^{a} \\
(0.010)\end{array}$ & & & $\begin{array}{l}-2.92^{\mathrm{a}} \\
(0.042)\end{array}$ & 0.068 & 66408 \\
\hline
\end{tabular}

Panel B: Piecewise linear regressions

\begin{tabular}{llrrrrrrr}
\hline & & & \multicolumn{7}{c}{ Reb } \\
& Sample & Const & Dummy & {$[\mathbf{0 , - 0 . 5 ]}$} & {$[-\mathbf{- 0 . 5 , - 5}]$} & {$[-\mathbf{- 5}, \infty]$} & Rsq & Obs \\
\hline \hline \multirow{2}{*}{ Model 5 } & \multirow{2}{*}{ Reb $<0$} & $0.241^{\mathrm{a}}$ & & 0.023 & $-0.331^{\mathrm{a}}$ & $0.06^{\mathrm{a}}$ & \multirow{2}{*}{0.108} & 20430 \\
& & $(0.026)$ & & $(0.084)$ & $(0.091)$ & $(0.018)$ & & \\
\hline \multirow{2}{*}{ Model 6 } & \multirow{2}{*}{ All } & $0.241^{\mathrm{a}}$ & $-0.084^{\mathrm{a}}$ & 0.023 & $-0.331^{\mathrm{a}}$ & $0.06^{\mathrm{a}}$ & 0.078 & 66408 \\
& & $(0.019)$ & $(0.020)$ & $(0.062)$ & $(0.068)$ & $(0.013)$ & & \\
\hline
\end{tabular}

a - Significant at the $1 \%$ level

b - Significant at the 5\% level 


\section{Table 6: Frequency of Put-Call Parity Violations After Transaction Costs}

The table reports the distribution of put-call parity of violations (in percent) after accounting for transaction costs in the options market. $S^{S}$ is the lower bound on the stock price as derived from put-call parity (the implied short stock price), $S^{M}$ is the stock price as derived from put-call parity when all option trades are traded at the midpoint, and $S^{L}$ is the upper bound on the stock price as derived form put-call parity (the implied long stock price). In Panel A we use the observed stock price S, while in Panel B we use the stock price adjusted for the rebate rate cost over the life of the option $\left(\mathrm{S}^{\mathrm{A}}\right)$, using the 2-state AR(1) model estimated in Table 3. The three test statistics test: (1) \& (2) whether the probability the stock price exceeds the upper bound is equal to the probability that the stock price is less than the lower bound for zero and negative rebate rate spread stocks, and (3) whether the probability of exceeding the upper bound is equal across zero and negative rebate rate spread stocks. The test statistics have an asymptotic $\mathrm{N}(0,1)$ distribution under the null hypotheses.

Panel A: Unadjusted stock price

\begin{tabular}{lrrrr}
\hline & $\mathbf{S}<\mathbf{S}^{\mathbf{S}}$ & $\mathbf{S}^{\mathbf{S}} \leq \mathbf{S}<\mathbf{S}^{\mathbf{M}}$ & $\mathbf{S}^{\mathbf{M}} \leq \mathbf{S} \leq \mathbf{S}^{\mathbf{L}}$ & $\mathbf{S}>\mathbf{S}^{\mathbf{L}}$ \\
\hline \hline All & 2.67 & 32.48 & 53.05 & 11.80 \\
Reb=0 & 2.71 & 34.33 & 54.26 & 8.70 \\
Reb $<0$ & 2.58 & 28.30 & 50.34 & 18.78 \\
\hline
\end{tabular}

\begin{tabular}{lcc}
\hline Test & Stat & P- value \\
\hline \hline $\operatorname{Pr}\left(S<S^{S} \mid \operatorname{Reb}=0\right)=\operatorname{Pr}\left(S>S^{L} \mid \operatorname{Reb}=0\right)$ & 39.21 & 0.00 \\
$\operatorname{Pr}\left(S<S^{S} \mid \operatorname{Reb}<0\right)=\operatorname{Pr}\left(S>S^{L} \mid \operatorname{Reb}<0\right)$ & 53.02 & 0.00 \\
$\operatorname{Pr}\left(S>S^{L} \mid \operatorname{Reb}=0\right)=\operatorname{Pr}\left(S>S^{L} \mid \operatorname{Reb}<0\right)$ & 37.14 & 0.00 \\
\hline
\end{tabular}

Panel B: Stock price adjusted for rebate rate cost

\begin{tabular}{lrrrr}
\hline & $\mathbf{S}<\mathbf{S}^{\mathbf{S}}$ & $\mathbf{S}^{\mathbf{S}} \leq \mathbf{S}<\mathbf{S}^{\mathbf{M}}$ & $\mathbf{S}^{\mathbf{M}} \leq \mathbf{S} \leq \mathbf{S}^{\mathbf{L}}$ & $\mathbf{S}^{2} \mathbf{S}^{\mathbf{L}}$ \\
\hline \hline All & 3.86 & 42.40 & 45.21 & 8.53 \\
Reb=0 & 3.62 & 42.51 & 47.27 & 6.60 \\
Reb $<0$ & 4.42 & 42.15 & 40.57 & 12.86 \\
\hline \multicolumn{4}{r}{ Stat } & P- value \\
\hline \hline $\operatorname{Pr}\left(\mathrm{S}<\mathrm{S}^{\mathrm{S}} \mid \operatorname{Reb}=0\right)=\operatorname{Pr}\left(\mathrm{S}>\mathrm{S}^{\mathrm{L}} \mid \operatorname{Reb}=0\right)$ & 20.55 & 0.00 & \\
$\operatorname{Pr}\left(\mathrm{S}<\mathrm{S}^{\mathrm{S}} \mid \operatorname{Reb}<0\right)=\operatorname{Pr}\left(\mathrm{S}>\mathrm{S}^{\mathrm{L}} \mid \operatorname{Reb}<0\right)$ & 30.39 & 0.00 & \\
$\operatorname{Pr}\left(\mathrm{S}>\mathrm{S}^{\mathrm{L}} \mid \operatorname{Reb}=0\right)=\operatorname{Pr}\left(\mathrm{S}>\mathrm{S}^{\mathrm{L}} \mid \operatorname{Reb}<0\right)$ & 26.67 & 0.00 & \\
\hline
\end{tabular}


Table 7: Put-Call Parity and Option Expiration

The table reports the distribution of the ratio $R \equiv 100 \ln \left(S / S^{*}\right)$ for at-the-money, short (30 to 90 days), intermediate (91 to 181 days) and long (182 to 365 days) maturity options (see Table 2 ). The four test statistics are described in Table 2.

\begin{tabular}{|c|c|c|c|c|c|c|c|c|c|}
\hline & \multicolumn{3}{|c|}{ Short } & \multicolumn{3}{|c|}{ Intermediate } & \multicolumn{3}{|c|}{ Long } \\
\hline & All & $\operatorname{Reb}=0$ & $\operatorname{Reb}<0$ & All & $\operatorname{Reb}=0$ & Reb $<0$ & All & $\operatorname{Reb}=0$ & $\operatorname{Reb}<0$ \\
\hline Obs & 63332 & 43664 & 19668 & 66408 & 45978 & 20430 & 27377 & 19026 & 8351 \\
\hline Mean & 0.21 & 0.14 & 0.36 & 0.29 & 0.16 & 0.6 & 0.35 & 0.14 & 0.84 \\
\hline \multicolumn{10}{|l|}{ Percentiles } \\
\hline 1 & -2.47 & -2.47 & -2.45 & -2.99 & -2.89 & -3.17 & -2.98 & -2.98 & -2.97 \\
\hline 5 & -1.03 & -1.00 & -1.10 & -1.21 & -1.17 & -1.28 & -1.17 & -1.15 & -1.21 \\
\hline 10 & -0.60 & -0.58 & -0.63 & -0.67 & -0.67 & -0.69 & -0.67 & -0.69 & -0.65 \\
\hline 25 & -0.14 & -0.14 & -0.13 & -0.17 & -0.18 & -0.13 & -0.20 & -0.23 & -0.10 \\
\hline 50 & 0.16 & 0.13 & 0.23 & 0.20 & 0.16 & 0.34 & 0.19 & 0.13 & 0.42 \\
\hline 75 & 0.51 & 0.44 & 0.69 & 0.64 & 0.52 & 0.99 & 0.67 & 0.51 & 1.24 \\
\hline 90 & 1.02 & 0.87 & 1.38 & 1.31 & 1.02 & 1.99 & 1.47 & 1.00 & 2.64 \\
\hline 95 & 1.51 & 1.26 & 2.09 & 1.94 & 1.46 & 2.97 & 2.29 & 1.49 & 4.02 \\
\hline 99 & 3.29 & 2.50 & 4.63 & 4.38 & 2.78 & 7.51 & 5.36 & 2.86 & 8.90 \\
\hline $\mathrm{R}<0(\%)$ & 35.15 & 36.32 & 32.55 & 35.14 & 37.04 & 30.88 & 36.75 & 40.01 & 29.33 \\
\hline $\mathrm{R}>0(\%)$ & 64.85 & 63.68 & 67.45 & 64.86 & 62.96 & 69.12 & 63.25 & 59.99 & 70.67 \\
\hline \multicolumn{2}{|c|}{ Test } & Stat & P-value & & Stat & P-value & & Stat & P-value \\
\hline \multicolumn{2}{|c|}{$\mathrm{E}[\mathrm{R} \mid \mathrm{Reb}=0]=\mathrm{E}[\mathrm{R} \mid \mathrm{Reb}<0]$} & 17.77 & 0.00 & & 27.28 & 0.00 & & 26.18 & 0.00 \\
\hline \multicolumn{2}{|c|}{$\operatorname{Pr}(\mathrm{R}>0 \mid \operatorname{Reb}=0)=50 \%$} & 57.16 & 0.00 & & 55.59 & 0.00 & & 27.56 & 0.00 \\
\hline \multicolumn{2}{|c|}{$\operatorname{Pr}(\mathrm{R}>0 \mid \operatorname{Reb}<0)=50 \%$} & 48.96 & 0.00 & & 54.67 & 0.00 & & 37.79 & 0.00 \\
\hline \multicolumn{2}{|c|}{$\operatorname{Pr}(\mathrm{R}>0 \mid \mathrm{Reb}=0)=\operatorname{Pr}(\mathrm{R}>0 \mid \mathrm{Reb}<0)$} & 9.21 & 0.00 & & 15.35 & 0.00 & & 16.88 & 0.00 \\
\hline
\end{tabular}




\section{Table 8: Structural Change}

Panel A reports the distribution of the ratio $R \equiv 100 \ln \left(S / S^{*}\right)$ (see Table 2) for 2 separate subperiods for at-the-money, intermediate maturity options (for negative rebate rate spread stocks only). The sample is divided by the technology crash into the subperiods July 1999 to February 2000 and May 2000 to November 2001. The two test statistics test for equality of means and the percentage of stocks with ratios greater than 0 across the two subperiods. The test statistics have an asymptotic $\mathrm{N}(0,1)$ distribution under the null hypotheses. Panel $\mathrm{B}$ reports regressions of $R$ on the rebate rate spread for negative rebate spread stocks for the 2 subperiods. The test statistic tests the equality of the coefficients on the rebate spread across the subperiods. Standard errors are in parentheses.

\section{Panel A: Distribution of unadjusted stock price ratios}

\begin{tabular}{lrrrr}
\hline & Mean & Median & R>0 (\%) & Obs \\
\hline \hline $7 / 99-2 / 00$ & 0.636 & 0.477 & 73.636 & 6380 \\
$5 / 00-11 / 01$ & 0.579 & 0.270 & 66.791 & 12909 \\
Stat & 1.812 & & 9.921 & \\
P-value & 0.035 & & 0.000 & \\
\hline
\end{tabular}

Panel B: Regressions

\begin{tabular}{ccccc}
\hline Sample & Const & Reb & Rsq & Obs \\
\hline \hline $7 / 99-2 / 00$ & $0.193^{\mathrm{a}}$ & $-0.312^{\mathrm{a}}$ & 0.099 & 6380 \\
& $(0.028)$ & $(0.012)$ & & \\
$5 / 00-11 / 01$ & $0.168^{\mathrm{a}}$ & $-0.264^{\mathrm{a}}$ & 0.121 & 12909 \\
& $(0.021)$ & $(0.006)$ & & \\
Stat & & 3.602 & & \\
P-value & & 0.000 & & \\
\hline
\end{tabular}

a - Significant at the $1 \%$ level

b - Significant at the 5\% level 


\section{Table 9: Stock Return Conditional Moments and Regressions}

Panel A reports the cross-sectional means and standard deviations of industry adjusted cumulative returns on stocks over the life of the options conditional on various values of the rebate rate spread and the unadjusted stock price ratio $R \equiv 100 \ln \left(S / S^{*}\right)$ (see Table 2 ). In each case, the test statistic tests whether the mean return equals zero. Panel B reports linear regressions of stock returns on rebate spreads and unadjusted stock price ratios. The dependent variable is the industry adjusted cumulative return on the stock over the life of the option. The independent variables are a zero rebate spread dummy that is equal to 1 if the firm has a zero rebate spread that day and 0 otherwise, the rebate spread for the firm that day (Reb), and the stock price ratio $R \equiv 100 \ln \left(S / S^{*}\right)$. All regressions have 57,019 observations. Standard errors are in parentheses.

Panel A: Conditional moments

\begin{tabular}{lccccc}
\hline Filter & Obs & Mean & StdDev & Stat & P-value \\
\hline \hline $\mathrm{Reb}=0 \%$ & 39993 & 0.212 & 38.964 & 1.089 & 0.862 \\
$\mathrm{Reb}<0 \%$ & 17026 & -6.853 & 48.337 & -18.498 & 0.000 \\
$\mathrm{Reb}<-0.5 \%$ & 7916 & -9.376 & 50.020 & -16.678 & 0.000 \\
$\mathrm{R}<0 \%$ & 20075 & -0.406 & 41.215 & -1.395 & 0.082 \\
$\mathrm{R}>0 \%$ & 36944 & -2.708 & 42.562 & -12.229 & 0.000 \\
$\mathrm{R}>1 \%$ & 8149 & -4.453 & 47.172 & -8.521 & 0.000 \\
$\mathrm{Reb}<0 \%, \mathrm{R}>0 \%$ & 11694 & -7.715 & 48.543 & -17.186 & 0.000 \\
$\mathrm{Reb}<-0.5 \%, \mathrm{R}>0 \%$ & 5774 & -10.593 & 50.633 & -15.897 & 0.000 \\
$\mathrm{Reb}<-0.5 \%, \mathrm{R}>1 \%$ & 4141 & -8.689 & 50.211 & -11.136 & 0.000 \\
$\mathrm{Reb}<-0.5 \%, \mathrm{R}>1 \%$ & 2891 & -11.947 & 51.802 & -12.400 & 0.000 \\
\hline
\end{tabular}

Panel B: Regressions

\begin{tabular}{lcccccc}
\hline & Const & Dummy & Reb & Reb $^{\mathbf{A}}$ & R & Rsq \\
\hline \hline Model 1 & $-1.581^{\mathrm{a}}$ & & & & $-1.149^{\mathrm{a}}$ & 0.002 \\
& $(0.179)$ & & & & $(0.118)$ & \\
\hline Model 2 & $-5.336^{\mathrm{a}}$ & $5.548^{\mathrm{a}}$ & $0.989^{\mathrm{a}}$ & & 0.007 \\
& $(0.369)$ & $(0.424)$ & $(0.118)$ & & \\
\hline Model 3 & $-5.224^{\mathrm{a}}$ & $5.541^{\mathrm{a}}$ & $0.812^{\mathrm{a}}$ & $-0.682^{\mathrm{a}}$ & 0.008 \\
& $(0.369)$ & $(0.424)$ & $(0.122)$ & & $(0.122)$ & \\
\hline Model 4 & $2.281^{\mathrm{a}}$ & & & $23.946^{\mathrm{a}}$ & & 0.006 \\
& $(0.279)$ & & & $(1.243)$ & & \\
\hline Model 5 & $2.154^{\mathrm{a}}$ & & & $22.282^{\mathrm{a}}$ & $-0.591^{\mathrm{a}}$ & 0.007 \\
& $(0.280)$ & & $(1.289)$ & $(0.122)$ & \\
\hline
\end{tabular}

a - Significant at the $1 \%$ level 


\section{Table 10: Portfolio Returns}

The table reports returns characteristics of portfolios formed based on trading signals relating to the rebate spread and the unadjusted stock price ratio $R \equiv 100 \ln \left(S / S^{*}\right.$ ) (see Table 2). All portfolios start on July 1999 and close on February 2002 for a total of 666 trading days. The portfolios have zero net investment and stocks are equally weighted each day. All portfolios short stocks with the relevant signal and go long an equal amount in a matched industry portfolio. Daily return is the average daily return on the portfolio; daily net return is the average daily return, net of the daily borrowing cost (rebate spread); STD net return is the daily standard deviation of the return on the portfolio; short obs is the average number of firms in the short portfolio per day.

\begin{tabular}{llcccc}
\hline Portfolio & Filter & Daily return & $\begin{array}{c}\text { Daily net } \\
\text { return }\end{array}$ & $\begin{array}{c}\text { STD net } \\
\text { return }\end{array}$ & Short obs \\
\hline \hline 1 & $\mathrm{Reb}<-0.5 \%$ & $0.070 \%{ }^{\mathrm{c}}$ & $0.06 \%$ & $1.02 \%$ & 212 \\
2 & $\mathrm{Reb}<-1.0 \%$ & $0.096 \%{ }^{\mathrm{b}}$ & $0.09 \%{ }^{\mathrm{b}}$ & $1.03 \%$ & 160 \\
3 & $\mathrm{R}>0 \%$ & $0.032 \%$ & $0.03 \%$ & $0.84 \%$ & 344 \\
4 & $\mathrm{R}>1 \%$ & $0.093 \%{ }^{\mathrm{b}}$ & $0.08 \%{ }^{\mathrm{b}}$ & $0.99 \%$ & 96 \\
5 & $\mathrm{Reb}<-0.5 \%, \mathrm{R}>0 \%$ & $0.121 \%{ }^{\mathrm{a}}$ & $0.11 \%{ }^{\mathrm{a}}$ & $1.07 \%$ & 85 \\
\hline
\end{tabular}

a - Significant at the $1 \%$ level

b - Significant at the 5\% level

${ }^{c}$ - Significant at the $10 \%$ level 


\section{Figure 1: Stock Price Ratios and Maturity}

The figure shows the fitted stock price ratio from regressions for short, intermediate and long maturity at-the-money options on the rebate rate spread. The sample period is July 1999 to November 2001, and Table 7 reports information on the maturity-sorted samples.

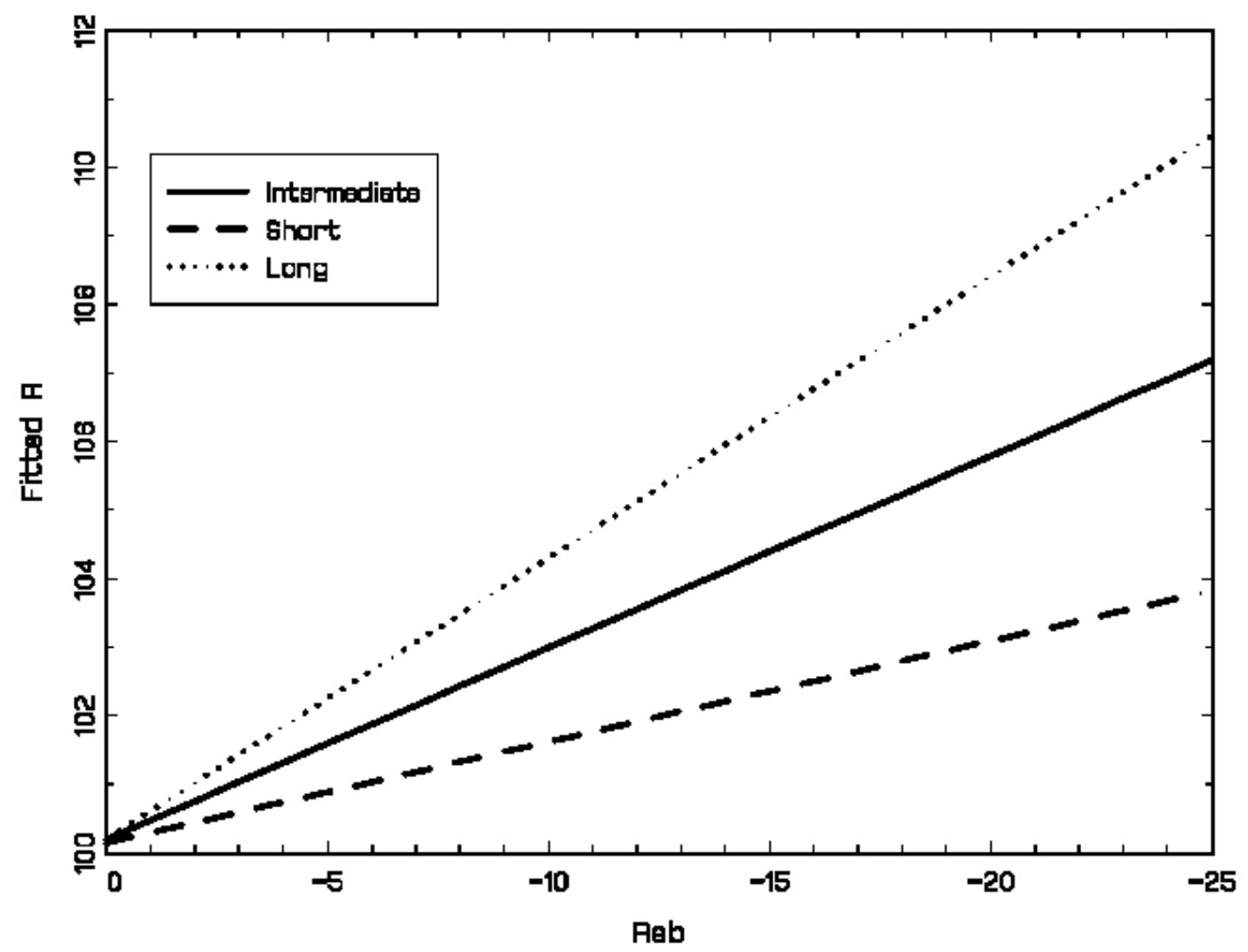




\section{Figure 2: Stock Price Ratios and PE Ratios Over Time}

The figure shows the median stock price $R$ for zero and negative rebate rate spread stocks for the at-the-money, intermediate maturity sample (left axis) and the average PE ratio of the S\&P500 (right axis) on a quarterly basis. The sample period is July 1999 to November 2001.

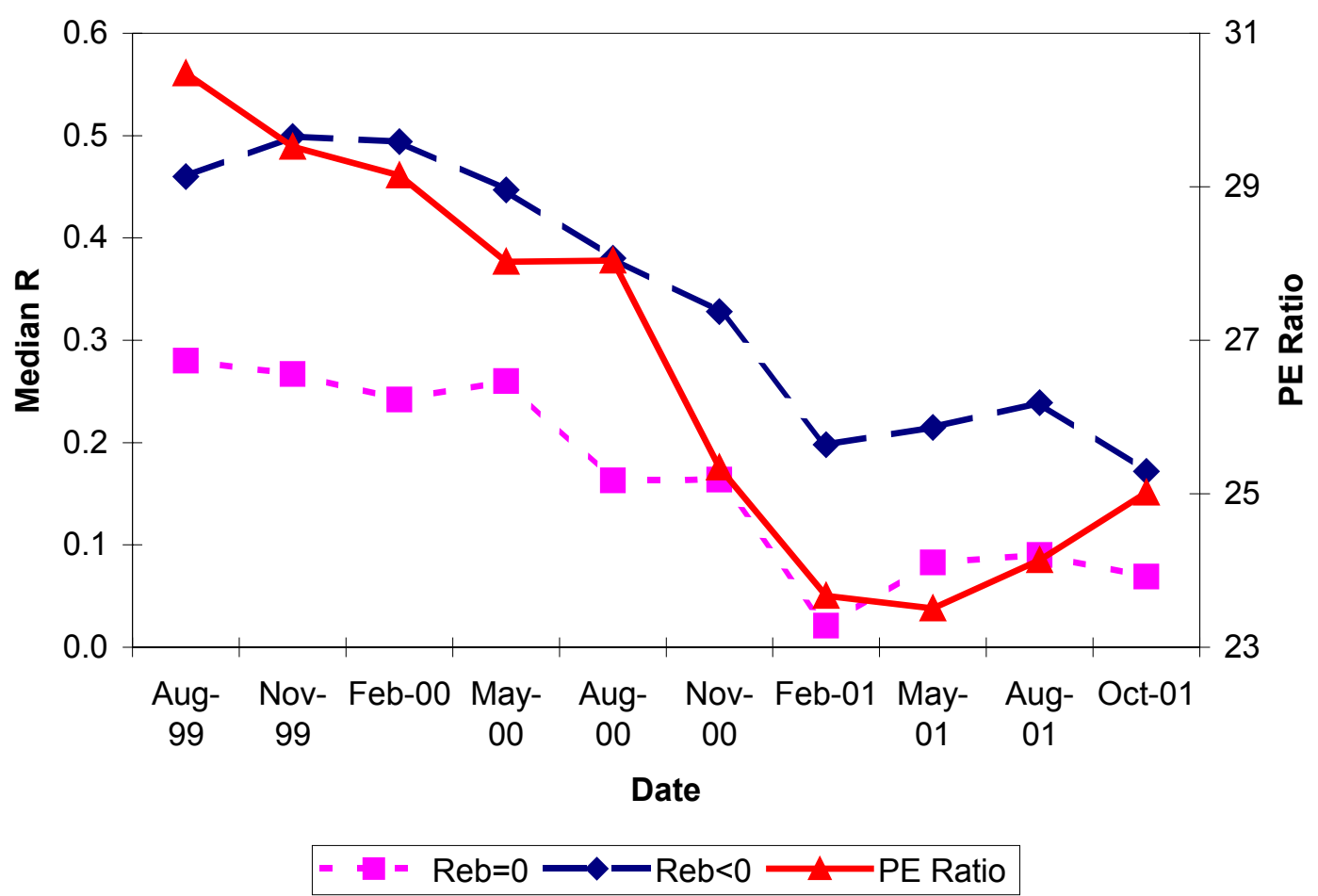




\section{Figure 3: Portfolio Returns}

The figure shows cumulative portfolio returns over the July 1999 to February 2001 period for three strategies that go short stocks based on rebate rate spread and stock price ratio signals and go long the corresponding industry portfolios. The returns are for portfolios 1, 3 and 5 from Table 10. Returns are net of shorting costs as measured by the rebate rate spread.

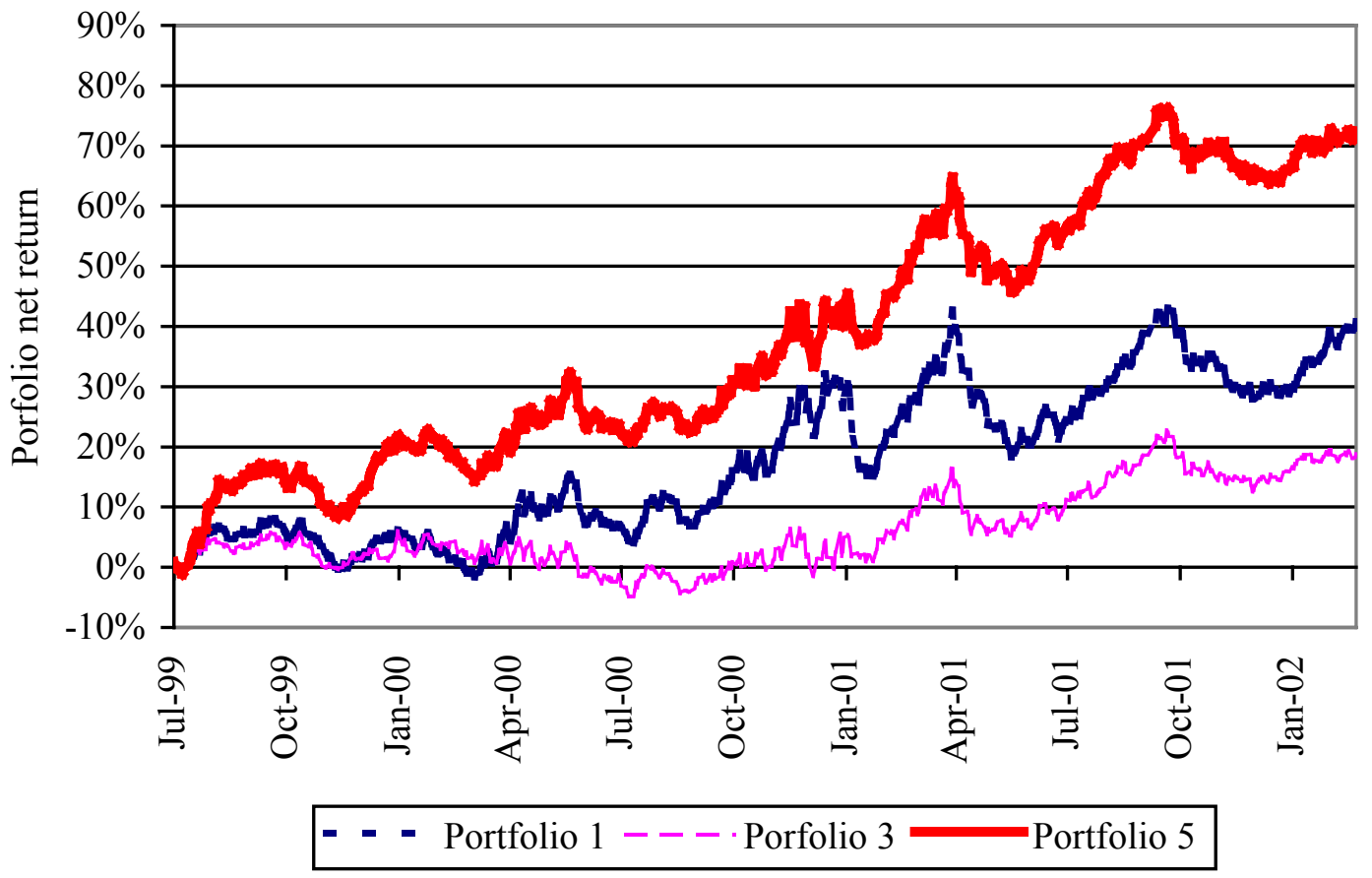

